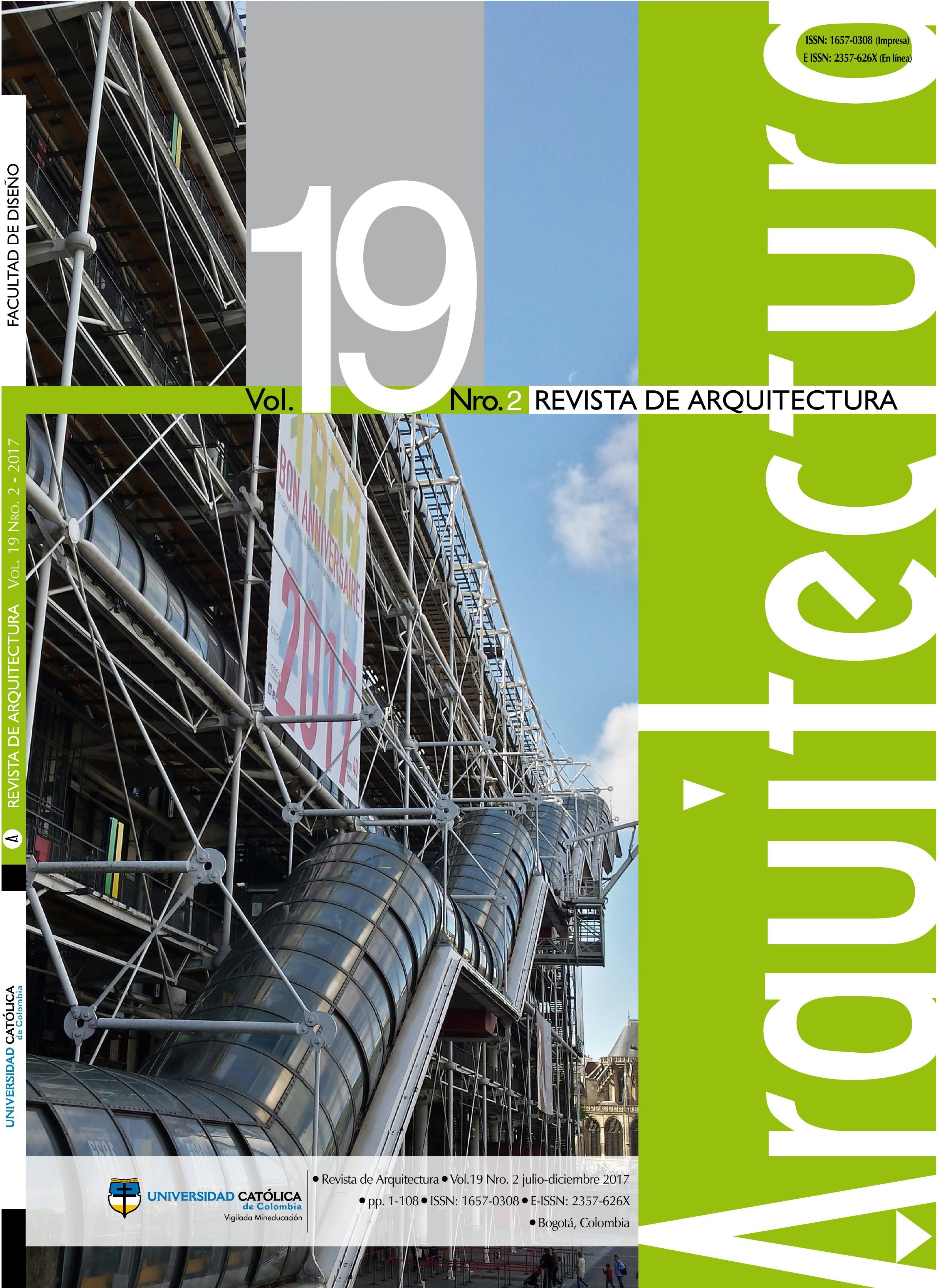


(A) Portada: Fachada principal del Centre Pompidou en su aniversario $n^{\circ} 40$ (Centro Nacional de Arte y Cultura Georges Pompidou de París-Francia) Fotografía: Andrés Ávila Gómez (Mayo de 2017)
A Orientación editorial

\section{Enfoque y alcance}

La Revista de Arquitectura (ISSN 1657-0308 Impresa y E-ISSN 2357-626X en línea) es una publicación seriada de acceso abierto, arbitrada mediante revisión por pares (doble ciego) e indexada, en donde se publican resultados de investigación originales e inéditos.

Está dirigida a la comunidad académica y profesional de las áreas afines a la disciplina. Es editada por la Facultad de Diseño y el Centro de Investigaciones (CIFAR) de la Universidad Católica de Colombia en Bogotá (Colombia).

La principal área científica a la que se adscribe la Revista de Arquitectura según la OCDE es:

Gran área: 6. Humanidades

\section{Área: 6.D. Arte}

Disciplina: 6D07. Arquitectura y Urbanismo

También se publican artículos de las disciplinas como 2A02, Ingeniería arquitectónica; 5G03, Estudios urbanos (planificación y desarrollo); 6D07, Diseño.

Los objetivos de la Revista de Arquitectura son:

- Promover la divulgación y difusión del conocimiento generado a nivel local, nacional e internacional

- Conformar un espacio para la construcción de comunidades académicas y la discusión en torno a las secciones definidas.

- Fomentar la diversidad institucional y geográfica de los autores que participan en la publicación.

- Potenciar la discusión de experiencias e intercambios científicos entre investigadores y profesionales.

- Contribuir a la visión integral de la arquitectura, por medio de la concurrencia y articulación de las secciones mediante la publicación de artículos de calidad.

- Publicar artículos originales e inéditos que han pasado por revisión de pares, para asegurar que se cumplen las normas éticas, de calidad, validez científica, editorial e investigativa.

- Fomentar la divulgación de las investigaciones y actividades desarrolladas en la Universidad Católica de Colombia.
Palabras clave de la Revista de Arquitectura: arquitectura, diseño, educación arquitectónica, proyecto y construcción, urbanismo.

Idiomas de publicación: español, inglés, portugués y francés.

Título abreviado: Rev. Arquit.

Titulo corto: RevArq

\section{Políticas de sección}

La revista se estructura en tres secciones correspondientes a las líneas de investigación activas y aprobadas por la institución, y dos complementarias, que presentan dinámicas propias de la Facultad de Diseño y las publicaciones relacionadas con la disciplina.

Cultura y espacio urbano. En esta sección se publican los artículos que se refieren a fenómenos sociales en relación con el espacio urbano, atendiendo aspectos de la historia, el patrimonio cultural y físico, y la estructura formal de las ciudades y el territorio.

Proyecto arquitectónico y urbano. En esta sección se presentan artículos sobre el concepto de proyecto entendido como elemento que define y orienta las condiciones proyectuales que devienen en los hechos arquitectónicos o urbanos, y la forma como estos se convierten en un proceso de investigación y nuevo de conocimiento. También se presentan proyectos que sean resultados de investigación, los cuales se validan por medio de la ejecución y transformación en obra construida del proceso investigativo. También se contempla la publicación de investigaciones relacionadas con la pedagogía y didáctica de la arquitectura, el urbanismo y el diseño.

Tecnología, medioambiente y sostenibilidad. En esta sección se presentan artículos acerca de sistemas estructurales, materiales y procesos constructivos, medioambiente y gestión, relacionados con los entornos social-cultural, ecológico y económico.

Desde la Facultad. En esta sección se publican artículos generados en la Facultad de Diseño, relacionados con las actividades de docencia, extensión, formación en investigación o internacionalización, las cuales son reflejo de la dinámica y de las actividades realizadas por docentes, estudiantes y egresados; esta sección no puede supera el $20 \%$ del contenido.

Textos. En esta sección se publican reseñas, traducciones y memorias de eventos relacionados con las publicaciones en Arquitectura y Urbanismo.
A Frecuencia de publicación

Desde 1999 y hasta el 2015, la Revista de Arquitectura publicó un volumen al año, a partir del 2016 se publicarán dos números por año en periodo anticipado, enero-junio y julio-diciembre, pero también maneja la publicación anticipada en línea de los artículos aceptados (versión Post-print del autor).

La Revista de Arquitectura se divulga mediante versiones digitales (PDF, HTML, EPUB, XML) e impresas con un tiraje de 1.000 ejemplares, los tiempos de producción de estas versiones dependerán de los cronogramas establecidos por la editorial.

Los tiempos de recepción-revisión-aceptación pueden tardar entre seis y doce meses dependiendo del flujo editorial de cada sección y del proceso de revisión y edición adelantado.

Con el usuario y contraseña asignados, los autores pueden ingresar a la plataforma de gestión editorial y verificar el estado de revisión, edición o publicación del artículo.
A Canje

La Revista de Arquitectura está interesada en establecer canje con publicaciones académicas, profesionales o científicas del área de Arquitectura y Urbanismo, como medio de reconocimiento y discusión de la producción científica en el campo de acción de la publicación.

Mecanismo

Para establecer canje por favor descargar, diligenciar y enviar el formato: RevArq FP20 Canjes

Universidad Católica de Colombia (2017,
julio-diciembre).
Revista de Arquitectura, 19(2),
I-108. Doi: 10.14718

ISSN: 1657-0308
E-ISSN: $2357-626 \mathrm{X}$
Especificaciones:
Formato: 34 × $24 \mathrm{~cm}$
Papel: Mate II5 g
Tintas: Negro y policromía

Contacto

Dirección postal:

Avenida Caracas No. 46-72

Universidad Católica de Colombia

Bogotá D.C.(Colombia)

Código postal: 111311

Facultad de Diseño

Centro de Investigaciones (CIFAR).

Sede El Claustro. Bloque "L", 4 piso

Diag. 46a No. 15b-10

Editor, Arq. César Eligio-Triana

Teléfonos:

+57 (1) $3277300-3277333$

Ext. 3109; 3112 o 5146

Fax: +57 (1) 2858895
Correo electrónico:

revistadearquitectura@ucatolica.edu.co cifar@ucatolica.edu.co

Página WEB:

www.ucatolica.edu.co

vínculo Revistas científicas

http://publicaciones.ucatolica.edu.co/ revistas-cientificas

http://editorial.ucatolica.edu.co/ojsucatolica/ revistas_ucatolica/index.php/RevArq 


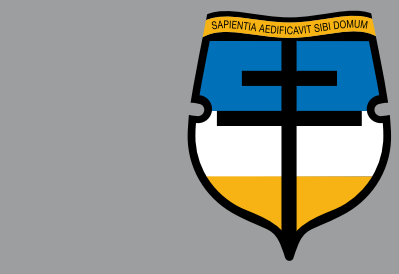

UNIVERSIDAD CATÓLICA de Colombia Vigilada Mineducación

\section{Universidad Católica de Colombia}

Presidente

Édgar Gómez Betancourt

Vicepresidente - Rector

Francisco José Gómez Ortiz

Vicerrector Jurídico

Edwin de Jesús Horta Vásquez

Vicerrector Administrativo

Édgar Gómez Ortiz

Decano Académico

Elvers Medellín Lozano

Directora de Investigaciones

Elisa Urbina Sánchez

Directora Editorial

Stella Valbuena García

\section{Facultad de Diseño}

Decano

Werner Gómez Benítez

Director de docencia

Jorge Gutiérrez Martínez

Directora de extensión

Adriana Pedraza Pacheco

Director de investigación

Hernando Verdugo Reyes

Director de gestión de calidad

Augusto Forero La Rotta

Comité asesor externo

Facultad de Diseño

Edgar Camacho Camacho

Lorenzo Castro

Giovanni Ferroni Del Valle

Alberto Miani Uribe

Martha Luz Salcedo Barrera

Samuel Ricardo Vélez

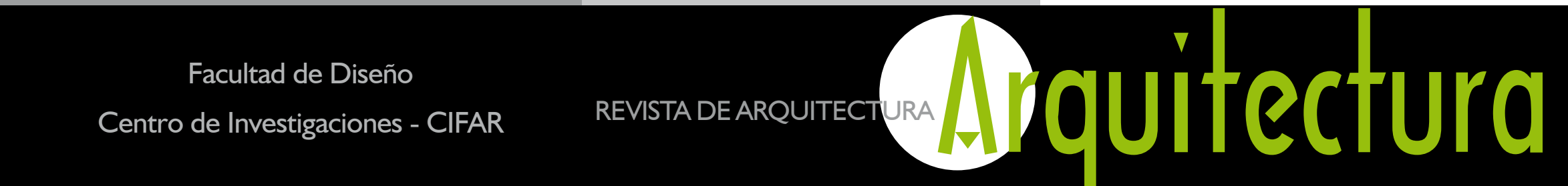

Revista de acceso abierto

arbitrada e indexada

Publindex: Categoría B. Índice Bibliográíco Nacional IBN.

Esci: Emerging Source Citation Index.

Doaj: Directory of Open Access Journ.

Redalyc: Red de Revistas Cientificas de América Latina y el Caribe,

España y Portugal.

Redib: Red lberoamericana de Innovación y Conocimiento Cientifico.

Ebsco: EBSCOhost Research Databases.

Clase: Base de datos bibliográfica de revistas de ciencias sociales y

humanidades.

Latindex: Sistema Regional de Información en Línea para Revistas

Cientificas de América Latina, el Caribe, España y Portugal (Director

y catálogo).

Dialnet: Fundación Dialnet - Biblioteca de la Universidad de La Rioja.

LatinRev: Red Latinoamericana de Revistas Académicas en Ciencias

Sociales y Humanidades.

Proquest: ProOuest Research Library.

Miar: Matrix for the Analysis of Journals.

Sapiens Research: Ranking de las mejores revistas colombianas según

visibilidad internacional.

Actualidad Iberoamericana: (Índice de Revistas) Centro de

Información Tecnológica (CIT)

Google Scholar

Arla: Asociación de Revistas latinoamericanas de Arquitectura.
Editoria

Av. Caracas $N^{\circ} 46-72$, piso 5

Teléfono: 3277300 Ext. 5145

editorial@ucatolica.edu.co

www.ucatolica.edu.co.

http://publicaciones.ucatolica.edu.co

Impresión:

JAVEGRAF

Calle 46A N 82-54 Int.

Bogotá, D. C., Colombia

http://www.javegraf.com.co/index.php

Diciembre de 2017

\section{Revista de Arquitectura}

Director

Werner Gómez Benítez

Editor

César Eligio-Triana

Editores de sección

(4) Myriam Stella Díaz Osorio

(1) Carolina Rodríguez Ahumada

(1) Anna Maria Cereghino Fedrigo

Consejo editorial

Werner Gómez Benítez

Jorge Gutiérrez Martínez

César Eligio-Triana

Hernando Verdugo Reyes

Equipo editorial

Coordinadora editorial

María Paula Godoy Casasbuenas

mpgodoy@ucatolica.edu.co

Diseño y montaje

Juanita Isaza

juanaisaza@gmail.com

Traductoras

Inglés

Erika Tanacs

etanacs25@gmail.com

Portugués

Roanita Dalpiaz

roanitad@gmail.com

Correctora de estilo

María José Díaz Granados M. mariajose_dgm@yahoo.com.co

Página Web

Centro de investigaciones (CIFAR)

Distribución y canjes

Claudia Álvarez Duquino

calvarez@ucatolica.edu.co
Comité editorial y científico

Carlos Mario Yory, PhD

Universidad Católica de Colombia. Bogotá, Colombia

Sonia Berjman, $\mathrm{PhD}$

ICOMOS-IFLA, Buenos Aires, Argentina

Juan Carlos Pérgolis, MSc Universidad Piloto de Colombia. Bogotá, Colombia

Beatriz García Moreno, PhD

Universidad Nacional de Colombia. Bogotá, Colombia

Proyecto arquitectónico y urbano

Jean-Philippe Garric, PhD, HDR

Université Paris I Panthéon-Sorbonne. Paris, Francia

Debora Domingo Calabuig, $\mathrm{PhD}$

Universidad Politécnica de Valencia, España

Hugo Mondragón López, PhD

Pontificia Universidad Católica de Chile. Santiago, Chile

Juan Pablo Duque Cañas, PhD

Universidad Nacional de Colombia. Bogotá, Colombia

Jorge Grané del Castillo, Msc

Universidad de Costa Rica. San José, Costa Rica

Tecnología, medioambiente y sostenibilidad

Mariano Vázquez Espí, PhD.

Universidad Politécnica de Madrid, España.

Luis Carlos Herrera Sosa, PhD

Universidad Autónoma de Ciudad Juárez, México

Claudio Varini, PhD

Universidad Católica de Colombia. Bogotá, Colombia

Luis Gabriel Gómez Azpeitia, PhD Universidad de Colima. Colima, México 


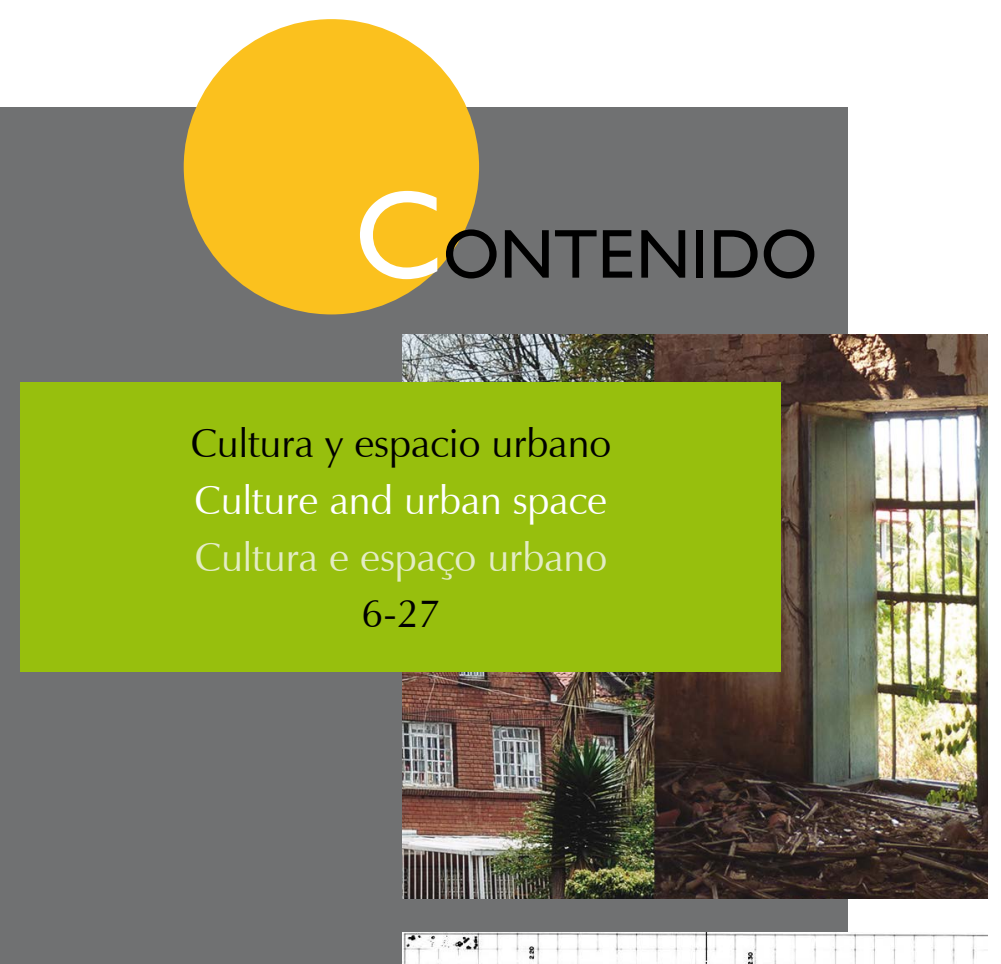

Editorial

Volver a la tradición mediante la innovación

Anna Maria Cereghino-Fedrigo

Pág. 3

Prácticas sociales frente al patrimonio cultural en Ambalema, Tolima

Juan Carlos Espinosa-Pasaje
Beatriz Helena Alba-Sanabria

Pág. 6

La noción de paisaje social

Un posible recurso para la valoración patrimonial

Alonso Gutiérrez-Aristizábal

Pág. 16

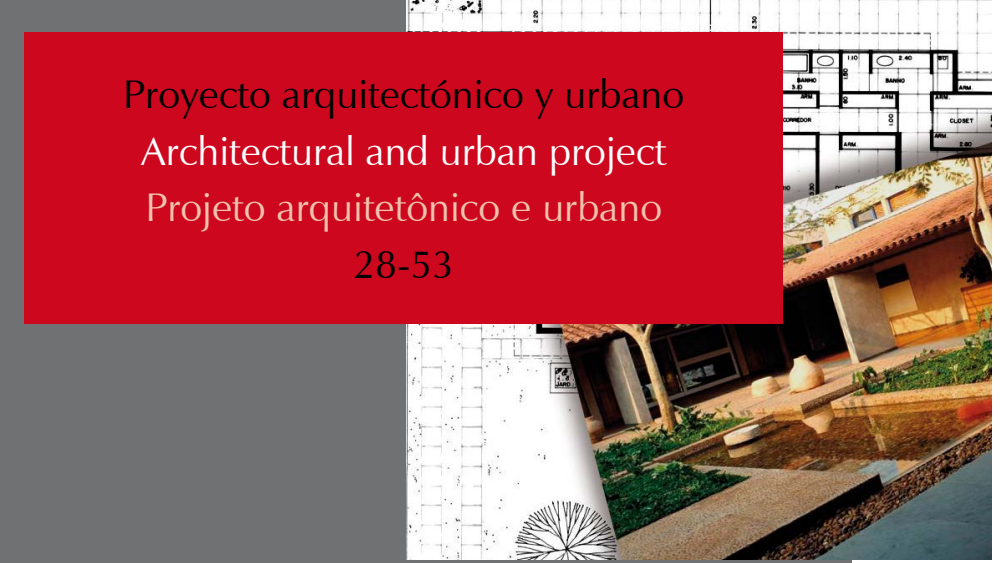

Cuadros de una exposición:

promenade architectural por la obra

de Eduardo de Almeida

Fernando Guillermo Vázquez-Ramos

Pág. 28

Evaluación posocupacional del grado de satisfacción de los trabajadores

Instituto de Planificación y Promoción de Soluciones

Energéticas para Zonas no Interconectadas (IPSE)

Mónica Dávila-Valencia
Andrés Felipe Ortiz-Silva

Karen Liliana Sánchez-Rincón

Pág. 44

Tecnología, medioambiente y sostenibilidad

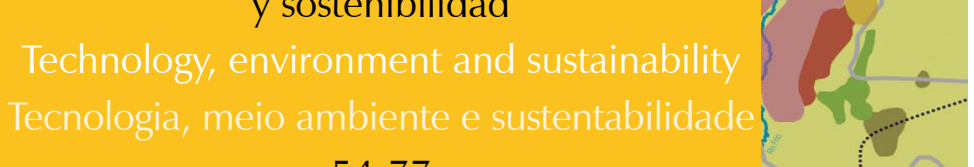
54-77

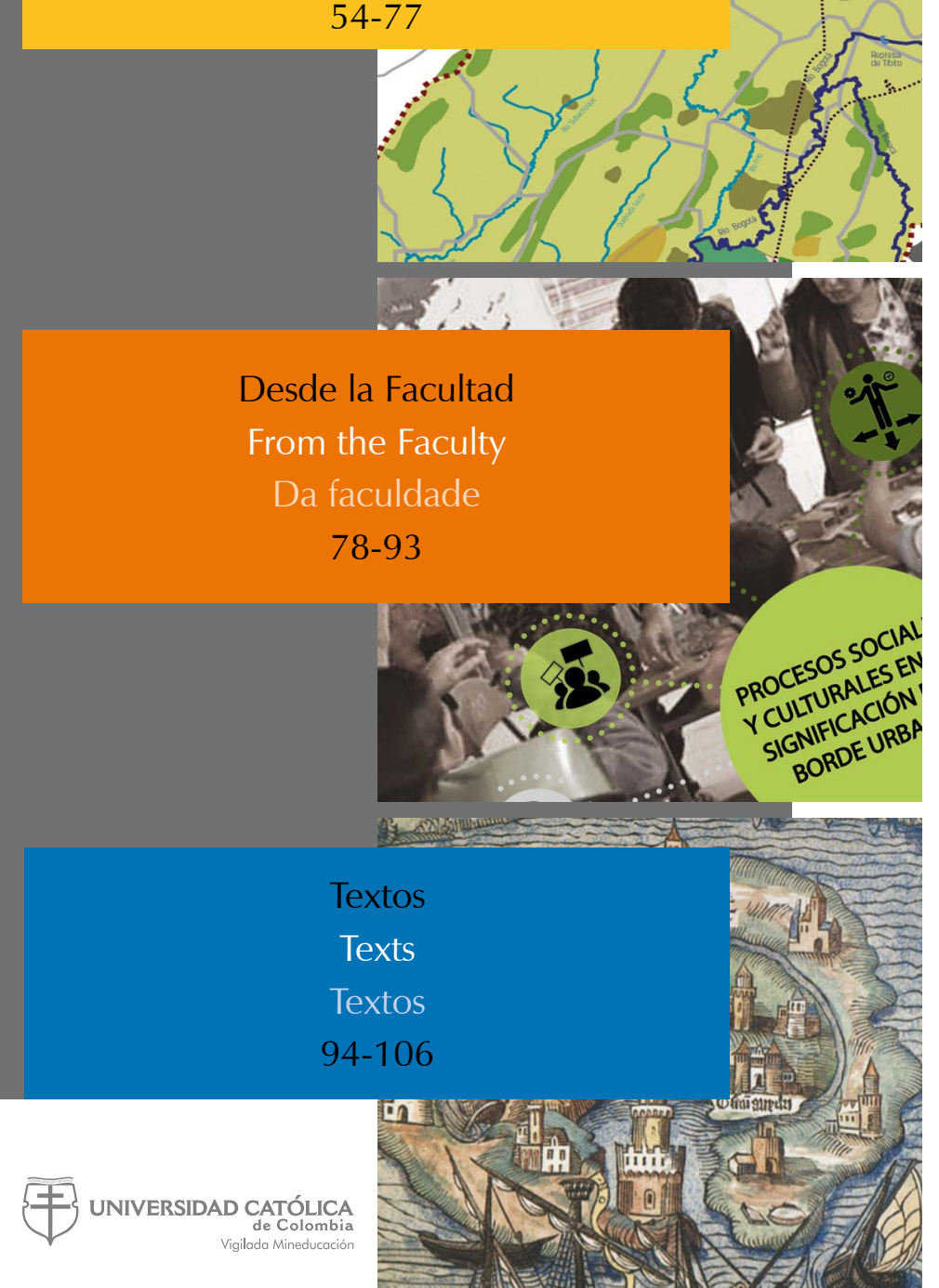

Comunidades resilientes:

tres direcciones integradas

Sandra Acosta-Guacaneme

Sandra Carolina Bautista-Bautista

Pág. 54

Innovación, design y sostenibilidad social:

nuevas tendencias para el desarrollo local en la

contemporaneidad

Pedro Arturo Martínez-Osorio

Marcia Barana

Rodrigo Rocha-Carneiro

Luis Carlos Paschoarelli

Pág. 68

Intervención social en el borde urbano desde

el proceso de la significación cultural

Fabián Adolfo Aguilera-Martínez
Marielena Medina-Ruiz
Colaboradores:
María Camila Castellanos-Escobar
Kelly Johanna Perilla-Agudelo

Pág. 78

Vectores de una cartografía teórica:

una brújula de navegación para un océano de

tesis doctorales en arquitectura

Jean-Pierre Chupin

Traductores:

Andrés Ávila-Gómez

Diana Carolina Ruiz 


\title{
Comunidades resilientes: tres direcciones integradas
}

\author{
Sandra Acosta-Guacaneme \\ Sandra Carolina Bautista-Bautista \\ Universidad de la Salle, Bogotá (Colombia)
}

Acosta-Guacaneme, S. y Bautista-Bautista, C. (2017). Comunidades resilientes: tres direcciones integradas. Revista de Arquitectura, 19(2), 54-67. doi: http://dx.doi.org/10.14718/ RevArq.2017.19.2.997

\author{
Sandra Acosta-Guacaneme \\ Arquitecta, Universidad de los Andes, Bogotá (Colombia). \\ Magíster en Paisajismo - Proyecto urbano (ENSAPLV), París (Francia) \\ Líder del proyecto de investigación "Diseño de lineamientos para la \\ implementación de ecobarrios y ecolades en áreas de borde urbano \\ para Bogotá D.C”. Profesora de planta e integrante del grupo de \\ investigación Marginalidad, Espacialidad y Desarrollo Sostenible \\ (MEDS) de la Facultad de Ciencias del Hábitat, Universidad de la \\ Salle, Bogotá (Colombia). \\ (Dhttp://orcid.org/0000-0002-1688-35IX \\ arquimatika@gmail.com - sanmacosta@unisalle.edu.co \\ Sandra Carolina Bautista-Bautista \\ Economista y magíster en Estudios Políticos, Universidad Nacional \\ de Colombia, Bogotá (Colombia). \\ Docente de planta; integrante del grupo de investigación Trabajo \\ Social, Equidad y Justicia Social; coordinadora de la línea de investiga- \\ ción e intervención en Derechos Humanos del programa de Trabajo \\ Social de la Universidad de la Salle, Bogotá (Colombia). \\ (Dhttp://orcid.org/0000-000I-6788-0792 \\ sancbautista@unisalle.edu.co
}

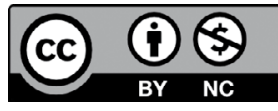

\section{Resumen}

Durante la última mitad de siglo Bogotá ha enfrentado procesos de crecimiento urbano que han afectado los ecosistemas y han generado empobrecimiento de las poblaciones asentadas en áreas de borde. Una alternativa factible a los retos de orden social y ambiental que enfrentan quienes habitan dichas áreas se encuentra en lo que en la investigación se denominó como comunidades resilientes. En este artículo se introduce la concepción y se muestran algunas propuestas que una política pública en la materia podría incorporar. Esto se genera a partir de una revisión teórica conceptual, y del análisis de experiencias existentes de ecobarrios y ecoaldeas en Bogotá y Cundinamarca. El objetivo principal es lograr un mejor hábitat con el entorno específico, donde la sustentabilidad sea la base. La normativa no es el único método que existe para la implementación, por esto se identifican estrategias en tres niveles: las de carácter top-down, otras en la vía del bottom-up y, finalmente, la articulación entre las dos anteriores mediante procesos de participación social.

Palabras clave: asentamientos humanos, derecho a la ciudad, ecobarrios, ecoaldea, políticas públicas, organización social, participación comunitaria, Región Administrativa de Planeación Especial (RAPE).

\section{Resilient Communities: Three Integrated Directions}

\section{Abstract}

During the last half of century, Bogota faced processes of urban growth that have affected the ecosystems and lead to the impoverishment of populations on the edge of settled areas. A feasible alternative to social and environmental challenges faced by those living in these areas lies in what research calls resilient communities. This article introduces the concept and describes some proposals that a public policy could include regarding the matter. This is based on a theoretical conceptual review, as well as on the analysis of existing experiences of eco-neighborhoods and eco-villages in Bogotá and Cundinamarca. The main objective is to achieve a better habitat within a specific environment, based on sustainability. Regulations are not the only method for its implementation; for this reason, the paper identifies strategies in three levels: those of top-down character, others in the bottom-up way, and, finally, an articulation between these two through processes of social participation.

Keywords: Human settlements, right to the city, eco-neighborhood, eco-village, public policies, social organization, community participation, Special Planning Administrative Region (RAPE).

\section{Comunidades resilientes: três direções integradas}

Resumo

Durante a última metade do século passado, Bogotá tem enfrentado processos de crescimento urbano que vêm afetando os ecossistemas e gerando empobrecimento das populações assentadas em áreas periféricas. Uma alternativa viável para os desafios de ordem social e ambiental que enfrentam os que habitam essas áreas se encontra no que, na pesquisa, se denominou como comunidades resilientes. Neste artigo, introduz-se a concepção dessa expressão e mostram-se algumas propostas que uma política pública na matéria poderia incorporar. Isso é gerado a partir de uma revisão teórica conceitual e da análise de experiências existentes de ecobairros e ecovilarejos em Bogotá e Cundinamarca. O objetivo principal é conseguir um melhor hábitat com o ambiente específico, onde a sustentabilidade seja a base. A normativa não é o único método que existe para sua implantação, por isso se identificam estratégias em três níveis: as de caráter top-down, outras na via do bottom-up e, finalmente, a articulação entre as duas anteriores mediante processos de participação social.

Palavras-chave: assentamentos humanos, direito à cidade, ecobairros, participação comunitária, políticas públicas, organização social, Región Administrativa de Planeación Especial (Rape). 


\section{Introducción}

La población en Bogotá se ha expandido considerablemente en los últimos cincuenta años. De acuerdo con el DANE, en 1964 el total de habitantes llegaba a 1.697.311, mientras que en 2010 las proyecciones establecían que la ciudad albergaba al menos a 7.563.782, en un proceso que mostró las mayores tasas de crecimiento en los años setenta y ochenta (Duque y Quintero, 2013). Tal situación ha generado múltiples asentamientos en áreas con diversidad de recursos, pero que no cuentan con condiciones de habitabilidad. Los bordes de la ciudad actual obedecen a límites naturales, es decir, a la estructura ecológica principal (EEP). La cantidad de población y asentamientos, tanto informales como formales, en estos territorios crece y con ella la destrucción del ambiente. Esta desarticulación entre medio-sociedad es una de las problemáticas esenciales del momento en la ciudad.

El presente artículo pone en evidencia algunos de los resultados más relevantes derivados del proyecto de investigación "Diseño de lineamientos para la implementación de ecobarrios o ecoaldeas en áreas de borde urbano de Bogotá D.C.", realizado a lo largo del año 2015 con el apoyo de la Vicerrectoría de Investigación y Transferencia de la Universidad de la Salle. Se trató de un ejercicio interdisciplinario que integró aportes de las ciencias del hábitat y las ciencias sociales con el objetivo de reconocer seis experiencias de ecobarrios y ecoaldeas en Bogotá y Cundinamarca en la última década, con el fin de identificar aportes con los cuales contribuir a la generación de política pública en la materia.

El ejercicio se articuló alrededor de la pregunta sobre posibles apuestas sustentables a las problemáticas de orden social y ambiental que se viven en las áreas de borde urbano en la ciudad de Bogotá. A partir de allí se evidenció la existencia de diferentes propuestas de ecobarrios que han sido ejecutadas en la capital del país desde principios del siglo XX, las cuales no han sido analizadas a profundidad. De tal manera, la investigación se propuso realizar un análisis de las características y dimensiones de las experiencias seleccionadas a fin de problematizar los elementos encontrados desde la perspectiva resiliente; a partir de lo anterior se identificaron propuestas para la configuración de comunidades con capacidad para afrontar los retos de la sustentabilidad en una ciudad como Bogotá.

Las nociones de ecobarrio y de ecoaldea han sido utilizadas desde los años ochenta para denotar espacios modificados por la acción humana, construidos con el fin de lograr el mayor nivel de armonía con el ambiente que los rodea. A nivel académico fueron Robert y Diane Gilman los primeros en acuñar el término (Álvarez, 2010), ampliamente extendido en los procesos urbanísticos, primero en Europa y Estados Unidos, para luego ser incorporados en los debates de América Latina. El análisis de la información recolectada a lo largo de la investigación propuso un nuevo escenario en el que se hizo pertinente reinterpretar estas categorías. A nivel global, los términos ecoaldea y ecobarrio tienen una carga significativa $y$, en general, están ligados con comunidades cerradas, lo que contrasta de manera contundente con los casos estudiados, ya que la posibilidad de configurar espacios para el logro de la sustentabilidad pasa por dos elementos fundamentales: la articulación de la comunidad al entorno en el que se encuentra y la configuración de procesos sociales que den vida a lógicas sustentables a nivel local. Surge así el interés por resignificar estas experiencias como comunidades resilientes, retomando aportes de autores como Joseba Azkarraga (2014).

En las ciencias ambientales, la discusión sobre resiliencia ha estado ligada tradicionalmente a la capacidad de respuesta de individuos, comunidades y colectivos frente a eventos que los ponen en situación de peligro. De ahí que los campos en los que tradicionalmente se ha implementado el enfoque han sido los de reducción de riesgos por desastres, la adaptación frente al cambio climático y la lucha contra la pobreza, en articulación con conceptos como el de vulnerabilidad. El enfoque de Azkarraga (2014) centra la atención en el papel de la resiliencia local y comunitaria, como estrategia para hacerle frente a fenómenos socioeconómicos y socioambientales. Tal situación deriva de la superación en los límites de uso y abuso de la naturaleza, e impone necesariamente un tránsito hacia formas diferentes de organización social, ambiental, económica y política. Analiza las "Iniciativas de transición", procesos organizativos de base que desde la cotidianidad realizan acciones para afrontar los desafíos de la crisis actual, a la par que desarrollan acciones ofensivas cuestionando las tendencias centrales de organización social, política, ambiental y cultural. Desde estas experiencias, el autor propone el concepto de resiliencia local y comunitaria, caracterizada por cuatro elementos:

a) Enfatizar la escala comunitaria.

b) Reivindicar la autonomía comunitaria.

c) por una participación ciudadana activa en relación con la sostenibilidad. 
d) Rehusar la implementación de modelos universales para la solución de problemas socioambientales.

De tal manera, en la investigación se identificó que las comunidades resilientes son más que un espacio físico localizado en zona urbana o limítrofe con la rural, en la cual se interviene desde lo externo. Más bien, se trata de un proceso organizado de la comunidad, es decir, de la creatividad colectiva organizada para la gestión-transformación del territorio, los recursos ambientales, sociales, culturales y económicos que este alberga, desde una perspectiva sustentable/sostenible, que le apuesta a la construcción de resiliencia local-comunitaria y para el ejercicio del derecho a la ciudad.

\section{Metodología}

El proceso de investigación partió de la revisión de literatura científica sobre ecobarrios, sostenibilidad y derecho a la ciudad, con el propósito de identificar el estado de la cuestión sobre el objeto de investigación seleccionado. De igual manera, se desarrolló una discusión teórico-conceptual que permitiera reflexionar sobre la ciudad en clave de desarrollo ambiental y sustentabilidad. Posteriormente, se realizó el análisis de tres iniciativas de ecobarrios o barrios que se pensaran en perspectiva de sostenibilidad en la ciudad de Bogotá -Urbanización Lombardía en Suba, Renacer en Bosa y El Triángulo y Aguas Claras en San Cristóbal-, asî como tres ecoaldeas ubicadas en el departamento de Cundinamarca -Organizmo, Monte Samai y Ecoaldea Feliz-. En todos los casos se trata de experiencias desarrolladas desde principios del siglo XX en Bogotá y sus áreas circunvecinas.

El estudio y la interpretación de los casos se realizó a partir de cinco dimensiones, derivadas del ejercicio de discusión teórica, que se consideraron como centrales para caracterizar los componentes esenciales de las comunidades resilientes: socioeconómica, sociopolítica, ambiental, de diseño en todas sus escalas desde lo urbano, pasando por lo paisajístico y su desarrollo puntual arquitectónico y objetual, y, claro está, la generación de procesos resilientes. Lo anterior, a partir de fuentes secundarias, visitas en las que se realizó tanto observación participante como entrevistas a profundidad con informantes clave, en este caso, líderes de las comunidades analizadas con amplio conocimiento en el proceso de configuración y funcionamiento de las eco aldeas y eco barrios.

Los procesos de tipo económico resultan cruciales dado que inciden de manera directa en el logro de la sustentabilidad, toda vez que las acciones realizadas por diversos sujetos en pro de solventar las necesidades de producción, cambio y consumo de bienes y servicios plantean una relación directa entre uso de recursos e impactos sobre el entorno. Desde el punto de vista de Azkarraga (2014), el problema de la sustentabilidad está relacionado con la posibilidad de "vivir bien dentro de los límites biofísicos del planeta", de lo que se deduce que el problema de uso y abuso de recursos resulta ser crucial para reflexionar sobre la manera de construir caminos hacia la sustentabilidad, por lo que se ha convertido en uno de los ámbitos clásicos sobre los cuales ha versado la discusión. De tal manera, en la investigación se asumió la categoría socioeconómica en procura de resaltar el papel de los sujetos en los procesos económicos, entendiendo a su vez que las variables de orden económico están en estrecha relación con las de orden social, organizativo y comunitario observadas en los casos seleccionados.

Así mismo, en la investigación se definió la dimensión sociopolítica como el conjunto de variables que, a nivel microsocial, abordan los procesos organizativos en función de la realización de comunidades resilientes: la construcción de redes de coordinación y trabajo, las diferentes formas en las que se realiza el proceso de toma de decisiones y las discusiones sobre cómo se involucra la comunidad en la definición de un horizonte colectivo de convivencia. Esta dimensión centró la mirada en los procesos de construcción de tejido social en torno al logro de la sustentabilidad en escala barrial, así como el desarrollo de actividades conjuntas y el uso de espacios comunitarios tendientes a la configuración de identidad y la cohesión social, elementos indispensables para la construcción de comunidades resilientes.

Por otro lado, la dimensión ecológico-ambiental proporcionó un indicio de cómo es la relación existente entre la sociedad y el resto de la naturaleza. La sostenibilidad se concentra en los flujos de materia y energía en los tres aspectos anteriores en busca de la calidad de ellos en pro del bienestar de los seres vivos en un ecosistema. Se trata de problematizar la rapidez a la que se explotan los recursos frente a la rapidez con la que estos se renuevan. Igualmente, mide el perjuicio que generan al ambiente los deshechos que producimos, y qué tanto aprovechamos fuentes de energía no convencionales (solar, eólica, biomasa, entre otras).

La dimensión de diseño urbano, del paisaje y arquitectónico tiene en cuenta la diversidad entre usos, estratos y biodiversidad; se revisan 
los servicios públicos, los espacios públicos, la infraestructura, su intensidad de uso, su movilidad, los equipamientos, aspectos de integración con el paisaje existente y las relaciones sociales que se generen. Se tiene en cuenta la densidad, que debe ser alta, manteniendo la calidad ambiental. En el objeto puntual, los materiales, la eficiencia y los procesos son básicos. La dimensión de resiliencia se tiene en cuenta la educación alternativa, el valor de lo local, la identidad, lo único, así como la vitalidad de la comunidad, el estado psicológico apoyado por la cultura y por el uso del tiempo libre y la calidad de vida.

\section{Resultados}

La discusión sobre las características, los alcances y presupuestos básicos de las experiencias seleccionadas, en contraste con los elementos teóricos, permitieron la formulación de un conjunto de estrategias para la implementación de comunidades resilientes en por lo menos dos niveles. El primero está enfocado en la política pública, en un acercamiento que se define como top-down. En un segundo plano se ubican algunas estrategias factibles de desarrollar desde lo comunitario, es decir una perspectiva cercana al bottom-up. A continuación, se presentan las propuestas para cada uno de los niveles enunciados.

\section{Top-down: propuesta de política pública con miras a las comunidades resilientes}

En el proceso de investigación se encontró que la construcción de política pública hacia el logro de comunidades resilientes debe estar enmarcada en una perspectiva regional, ya que la interrelación de la comunidad con otros niveles territoriales es un punto nodal para la construcción de una perspectiva sustentable.

En ese sentido, la primera escala de intervención identificada fue la regional, que al integrarse al entramado nacional apunta a la creación y puesta en marcha de la región central y del área metropolitana. En términos de los instrumentos vigentes de política pública, se encuentra que es factible darle sustento a la mencionada área metropolitana a través de lo dispuesto en la Ley 1454 de 2011, que en el artículo 30 viabiliza la configuración de la Región Administrativa de Planeación Especial (RAPE). De acuerdo con la Secretaría de Planeación (2015), la RAPE está compuesta por 22 de los 116 municipios de Cundinamarca: Cogua, Nemocón, Gachancipá, Tocancipá, Sopó, La Calera, Chía, Cajicá, Funza, Mosquera, Bojacá, Zipacón, Facatativá, Madrid, Tenjo, El Rosal, Subachoque, Tabio, Zipaquirá, Soacha, Sibaté y Bogotá urbana y rural.
Es importante entender este instrumento administrativo dentro de las lógicas de la región compacta para potenciar de manera efectiva sus beneficios a nivel tanto de movilidad como los de tipo económico, entendiendo los núcleos urbanos como polifuncionales. En esta primera escala se debe reforzar la conectividad nacional apelando a varios medios de transporte colectivos y masivos, que cuenten con tiempos cronometrados, $y$, sobre todo, que respondan a un sistema integral con efectiva capacidad de movilización de la población. De igual manera, es perentorio generar un plan rural para consolidar la región central desde una perspectiva sustentable, productiva y que respete los límites del ecosistema.

Así mismo, y desde la perspectiva de las propuestas generadas en el marco del proyecto de investigación, se identificó que en los procesos de planificación regional se le debe dar relevancia efectiva a la estructura ecológica regional (EER) y vincularla directamente con la estructura ecológica principal del Distrito Capital (EEP). Según el Decreto 3600 de 2007 del Ministerio del Medio Ambiente, la estructura ecológica se entiende como: “El conjunto de elementos bióticos y abióticos que dan sustento a los procesos ecológicos esenciales del territorio, cuya finalidad principal es la preservación, conservación, restauración, uso y manejo sostenible de los recursos naturales renovables, los cuales brindan la capacidad de soporte para el desarrollo socioeconómico de las poblaciones".

De tal manera, la realización efectiva de este instrumento en el caso de la región y del Distrito se convierte en una estrategia para manejar la huella ecológica, el cambio climático, la mitigación de riesgos y preservación de los ecosistemas presentes. Este esquema para la organización de lo ambiental se tiene que desarrollar de acuerdo con las características del territorio, los ecosistemas y las unidades de paisaje que están inmersas en este gran territorio regional. Como estrategia primordial debe haber un organismo que regule y mantenga la EEP del Distrito Capital, así como la EER.

La estructura ecológica regional y la estructura ecológica principal de Bogotá y su área metropolitana se asocian a las zonas altas de montaña (entre ellas el páramo), a las zonas inundables asociadas a los humedales, y a las cuencas de los ríos principales de la región metropolitana (Figura 1, p. 58).

Del mismo modo, para la preservación de la EEP resulta fundamental controlar la expansión de los asentamientos urbanos y velar por una ciudad compacta en términos de planificación, según lo que postula Richard Rogers (2000) en 
(1) Figura 1. Estructura ecológica regional y estructura ecológica principal del Distrito Capital

Fuente: elaboración propia, 2016, sobre plano base Gobernación de Cundinamarca. Instituto

Geográfico Agustín Codazzi (IGAC) (2013). CC BY-NC.

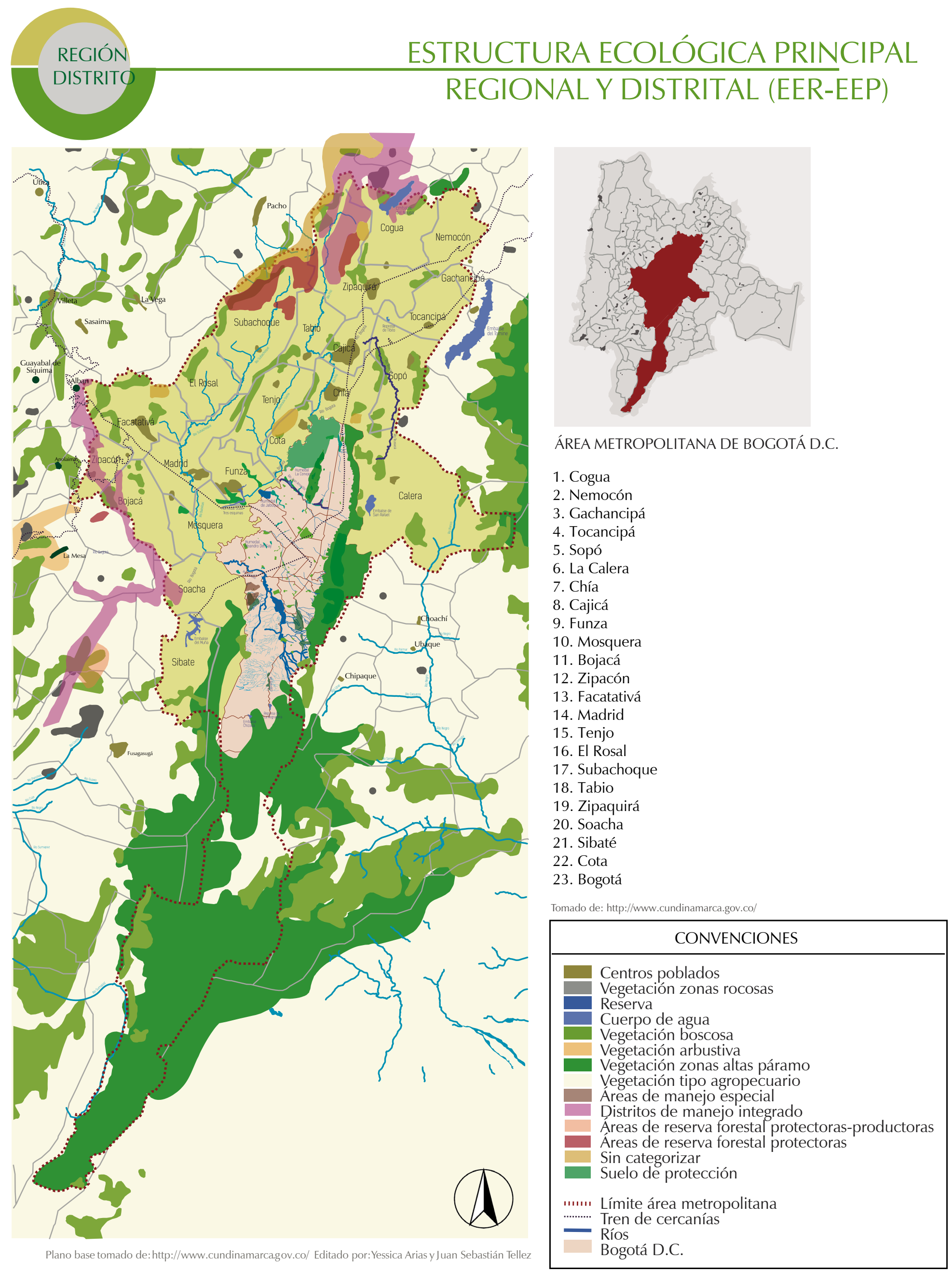


el libro Ciudades para un pequeño planeta, de manera que los crecimientos urbanos se den al interior del suelo urbano legal determinado. Así mismo, el asunto en el ámbito rural también debe ser reglamentado con una normativa no singular, sino aplicada a la región metropolitana, en la cual haya complementariedad. Como medida se debe proteger la EEP de la ciudad para que esta recupere su ciclo natural y su continuidad intrínseca, propia del territorio. Para ello se precisa restaurar las rondas de los ríos principales de la ciudad, gravemente afectadas desde los años setenta por la tardía ingeniería de rectificación de cauces y canalización, cuyo resultado más evidente al día de hoy es la conversión de ríos principales en caños.

Resulta fundamental entender la importancia del agua, de las cuatro cuencas principales y de todas las quebradas que bañan el espacio construido del Distrito Capital. Es por esto que las cuencas de estos ríos deben renaturalizarse, generar una conversión a lo que era anteriormente una sábana con ríos y vegetación fuerte y nativa como representante de una ciudad tropical de montaña.

En esta misma línea, es importante generar un organismo encargado de la EEP, este debe otorgar áreas de control, y hacer un monitoreo constante para ver su proceso de recuperación en el tiempo, para hacer cumplir los límites y garantizar que nuestros recursos se preserven, al igual que un reconocimiento de todos los ecosistemas al interior de la EEP, así podríamos entender la biodiversidad existente.

La segunda estrategia en esta escala es la de desarrollo del ecoturismo, teniendo en cuenta las cualidades inherentes de la EEP y sus múltiples potenciales. La iniciativa ecoturística se lleva a cabo a nivel nacional y está relacionada con los parques nacionales naturales de Colombia, pero esta iniciativa debe volverse fuerte a nivel Distrital y regional. Para lograr esta estrategia se propone la creación de una rama en el Fondo Nacional de Turismo (Fontur), que se encargue del desarrollo pero a nivel distrital y regional. Esta entidad daría paso a los diferentes lugares asociados al ecoturismo en la región metropolitana, teniendo en cuenta los parques nacionales existentes, escenarios de alta montaña y páramo, y otros escenarios reconocidos por sus calidades ecológicas como son las cuencas, los humedales y los parques ecológicos.

En la Figura 2 (p. 60) se evidencia el arqueo de diferentes ecosistemas ubicados tanto en la EER como en la EEP (zonas inundables, de montaña, de páramo, de reserva, de manejo especial, de protección, parques ecológicos, parques nacionales naturales, tipos de vegetación, cuerpos de agua y cuencas) realizado durante la investigación, en los que existen fuertes potenciales para el desarrollo ecoturístico.
En la escala distrital se proponen dos estrategias, la primera está relacionada con el manejo de la estructura ecológica principal a nivel distrital y su relación con la región, como lo mencionamos. Y dentro de esta EEP se debe ver el papel de los botaderos o rellenos sanitarios: el primero es Doña Juana, localizado en el sur de la ciudad, cerca de uno de los principales cauces de la capital como es el río Tunjuelito; el segundo es el de Mondoñedo, localizado en el municipio de Mosquera, al occidente de Bogotá. Estos dos rellenos sanitarios deberían tener políticas de sustentabilidad, donde los residuos se manejen en ciclos, y donde el área dispuesta sirva como parque metropolitano. Se toma como ejemplo Buenos Aires, ciudad en la que el principal relleno sanitario, Ceamse, es un parque metropolitano: "el predio de la Ceamse recibe 15.000 toneladas diarias y está cerca de saturarse. Pero sobre los rellenos hay espacios verdes, animales y casi no se siente el olor. Allí reciclan y hasta generan energía eléctrica" (Novillo, 2015).

Estos espacios en la ciudad deben ser vistos como partes generadoras de nuevas soluciones, a la par que se convierten en lugares de creación por excelencia, ejemplo de transformación, de pensamiento, de ciclos de oportunidad para la investigación. Donde se pueda aplicar de lleno la teoría de las 4R: Reducir, Reusar, Reciclar y Recrear, mencionada por McDonough (2002).

Como segunda estrategia se plantea una política que ayude a darle límite al crecimiento de la población; es necesaria una política clara en cuanto al crecimiento demográfico y, por ende, a la ocupación del territorio urbano disponible para tal efecto. Como señalan Carrizosa y Ruiz (2016): "no hay una política clara respecto al crecimiento demográfico ni una política de ocupación del espacio".

De acuerdo con los datos compilados en Bogotá Humana, un documento realizado por el Centro de Estudios y Análisis en Convivencia y Seguridad Ciudadana (Ceacsc) de la anterior administración, en el periodo de enero a junio de 2014 se puede ver que la mayoría de adolescentes embarazadas (de 10 a 18 años de edad) están en la periferia del Distrito Capital (Ceacsc, 2014). Esta es una problemática abrumadora, ya que muchos de estos niños son fruto de problemas aún mayores como el abuso sexual, la violencia intrafamiliar, entre otros. Esta situación, a su vez, genera otras problemáticas como el abandono de la educación, el trabajo infantil mal remunerado, ahondando cada vez en el escenario de pobreza, desigualdad, problemas de género, etc. Para poder cambiar esta situación es necesario adelantar campañas hacia la salud sexual y reproductiva, y planificar en el territorio, en el suelo urbano ya determinado. 


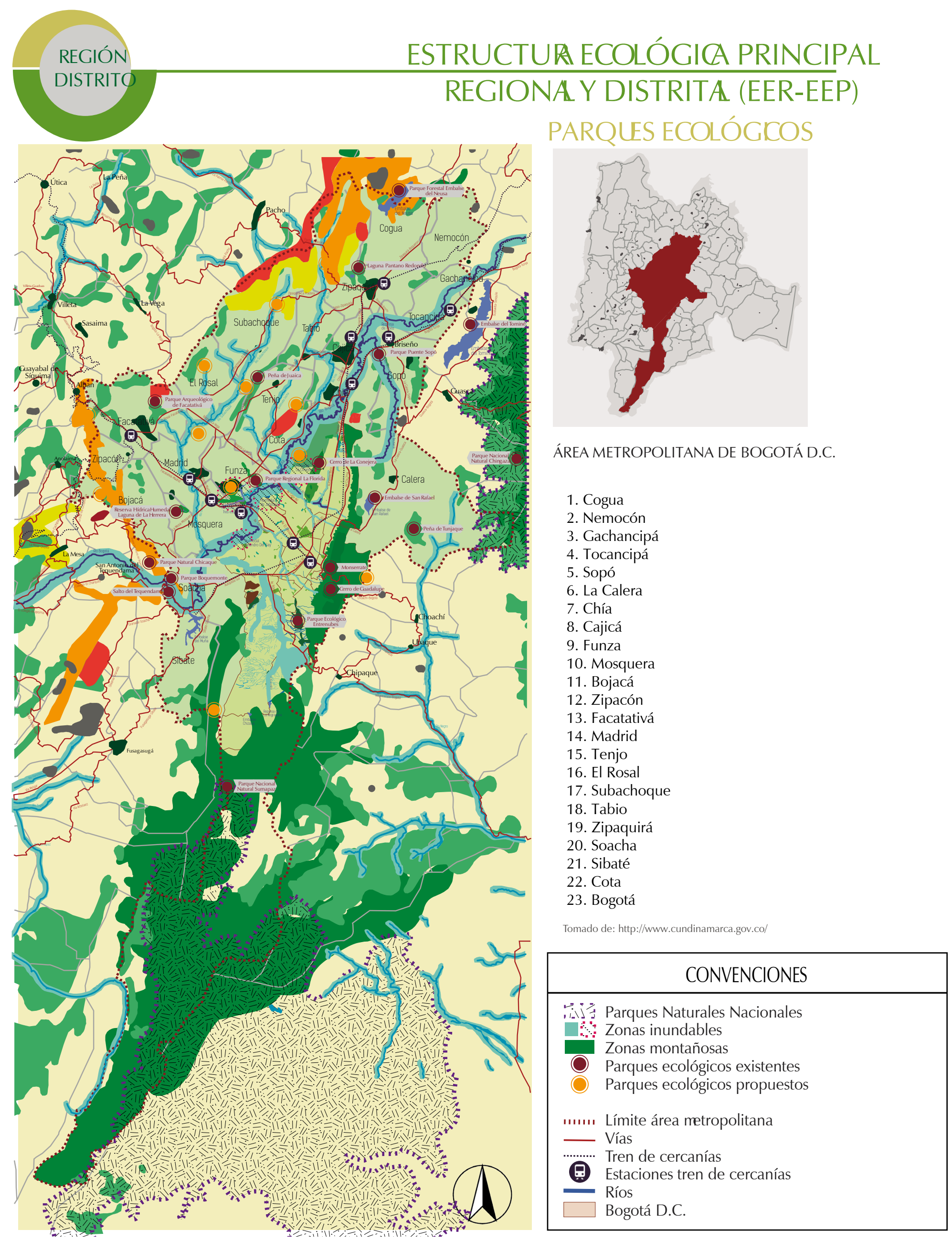


Bogotá está compuesta por 20 localidades, cada una de las cuales tiene una Alcaldía local que representa el poder distrital (Figura 3). Una de las estrategias fundamentales a nivel local está
(7) Figura 3. Las localidades de Bogotá

Fuente: elaboración propia, 2016, sobre plano base Decreto 364, 2013, Planeación Distrital (2013). CC BY-NC.

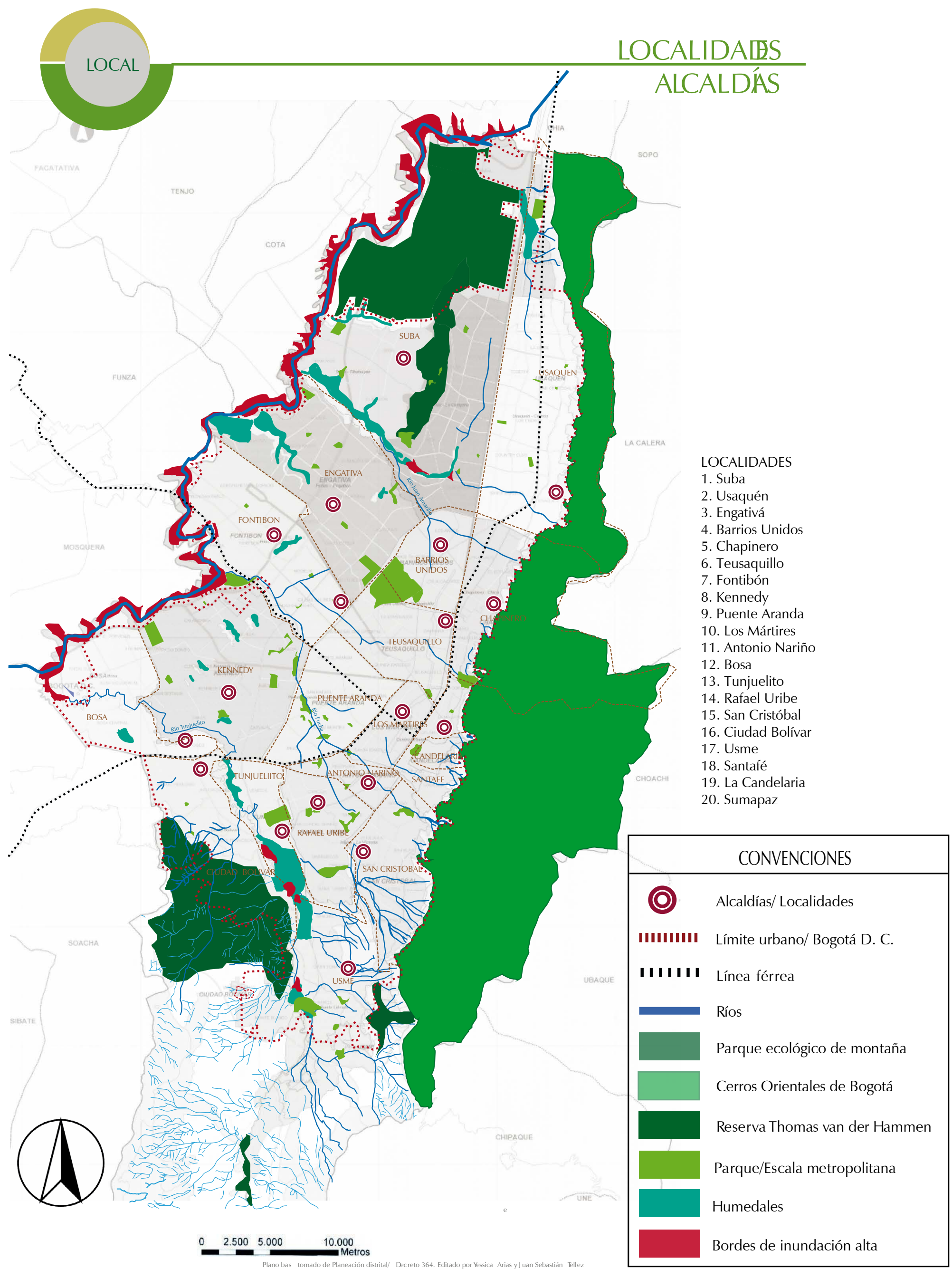


relacionada con la educación alternativa, experimental y en horarios flexibles, dirigida a todos los miembros que componen la localidad, una población tan diversa como sus intereses. Esto con el fin de generar comunicación entre las diferentes personas de la comunidad y poder utilizar el tiempo libre. Se busca entonces dar lugar a diferentes miradas para esta educación, enfocadas en cinco campos específicos: el sociopolítico, el socioeconómico, el medioambiental, el diseño y la resiliencia.

Esta educación a nivel local puede estar reforzada por cada una de las alcaldías, a fin de que esté bien equipada a nivel humano y a nivel de herramientas. Es necesario un equipo profesional en diferentes ramas, por ejemplo: trabajadores sociales, psicólogos, arquitectos, urbanistas, diseñadores, administradores, entre otros, con especial énfasis en los aspectos que caracterizan las comunidades resilientes.

En la Figura 4 se resumen las propuestas a nivel macro, en las escalas regional, distrital y local, cada una de las cuales plantea las estrategias y acciones necesarias para la correcta implementación de la propuesta.

\section{Bottom-up: propuestas a nivel microsocial, lo barrial}

(A) Figura 4. Resumen propuestas a nivel macro Fuente: elaboración propia, 2016. CC BY-NC-SA.
Tal y como se planteaba inicialmente, las comunidades resilientes son ante todo un proceso social que se configura a nivel local a partir de la necesidad de dar respuesta a los retos que se derivan de una perspectiva sustentable de ciudad, en la que la cohesión y el compromiso de los habitantes son determinantes. Es más, se puede afirmar que el nivel de apropiación de la comunidad frente a la trascendencia de los problemas ambientales y a la necesidad de plantear soluciones de orden colectivo es un factor determinante para dar paso a una propuesta de estas características. En momentos previos y durante el primer gobierno de Antanas Mockus (19951997), la Alcaldía Mayor de Bogotá puso en marcha iniciativas para desarrollar ecobarrios en las veinte localidades de la ciudad. Dicha experiencia dejó como una de sus principales enseñanzas que el papel de la política pública en función del fortalecimiento organizativo debe estar encaminado hacia el soporte de iniciativas comunitarias, pero no puede someterlas a objetivos prefijados con antelación, desde arriba y por fuera de los intereses de la propia comunidad (Rojas, 2003).

Las propuestas que involucren a la población son fundamentales, de ahí que la participación se convierta en un tema crucial. A continuación se presentan los principales resultados de la experiencia evidenciada en la investigación en el caso de la Ecoaldea Feliz, el más representativo, exitoso y estable entre los analizados.

\section{La experiencia de participación en la}

\section{Ecoaldea Feliz}

Ubicada en el municipio de San Francisco, Cundinamarca, la Ecoaldea Feliz es un proyecto
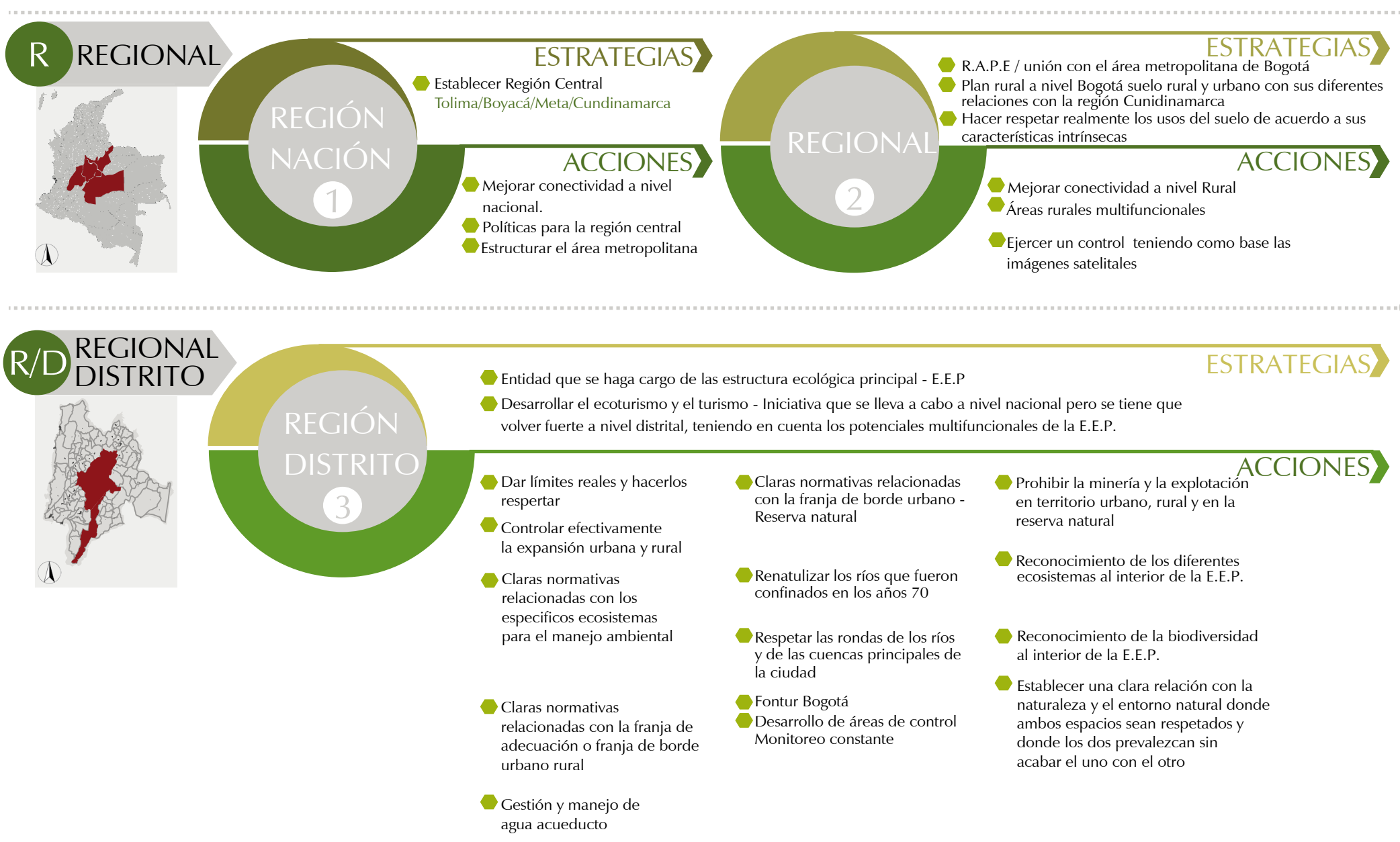
de convivencia sustentable, es decir de Comunidad Resiliente, puesto en marcha desde abril de 2006. Al momento de las visitas y entrevistas -año 2015-, vivían allí 30 personas, 12 niños y 18 adultos, ubicados en espacios de autoconstrucción a partir de insumos locales, con pleno reconocimiento los ciclos tanto de los materiales como de los procesos. Se evidenció la existencia de un control a nivel del área de vivienda: $25 \mathrm{~m}^{2}$ /persona, $50 \mathrm{~m}^{2} /$ pareja y máximo $70 \mathrm{~m}^{2} /$ familia, independientemente de la cantidad de personas que la componen, así como la configuración de normas para el control de la población, como la de 1 casa/ha. La diversidad en un sentido amplio es el eje central de esta propuesta, ya que se observa la integración de diferentes tipos de actividades productivas que procuran ser sustentables, como actividades que potencian la comunicación permanente entre quienes habitan la Ecoaldea, con espacios colectivos como el taller creativo, el almacén de materiales y el Cusmuy o casa ceremonial.

La dinámica sociopolítica es una de las que más cambios ha presentado a lo largo de los nueve años de historia de la ecoaldea, a la vez que se ha convertido en uno de los pilares fundamentales del proceso. Según lo expresado por los líderes de la eco aldea, existe un sistema de gobernanza específico denominado sociocracia, configurado y seleccionado posterior a la implementación de diferentes modos de organización (López y Jaramillo, 2015). El punto central de debate ha sido la forma en la que se toman y ejecutan las decisiones, en tanto que el primer modelo de organización asumido se inclinaba por una lógica permanente de consenso total y consulta frente a cada una de las decisiones que se debía tomar en los más variados campos, desde las relacionadas con la producción hasta las de pertenencia a la ecoaldea. Los testimonios obtenidos permiten evidenciar que tal modelo se hizo complejo, particularmente porque generaba talanqueras al momento de definir y ejecutar. De tal manera, lo que en principio pretendía generar sentido de pertenencia y crear capacidad colectiva de decisión, terminó por generar un relativo inmovilismo que detuvo varios proyectos e iniciativas. No obstante, los líderes de la ecoaldea rescataron tal discusión al considerarla como un momento necesario que permitió la configuración de la misión y visión del proceso.

En este marco apareció la propuesta de la sociocracia, una de las alternativas planteadas desde la Red Colombiana de Ecoaldeas y Comunidades Alternativas, (Renace), a la que se encuentra vinculada la Ecoaldea Feliz. De acuerdo con los dirigentes entrevistados (López y Jaramillo, 2015), los objetivos centrales de tal apuesta organizativa son el mejoramiento continuo de la comunidad, fundado en pilares como participación, discusión, inclusión, ejecución y evaluación; retoma la perspectiva de holocracia, forma de organización que valora la autonomía y la dependencia de las partes que componen un sistema y propende por distribuir la autoridad de manera horizontal, por lo

\section{Oxamo

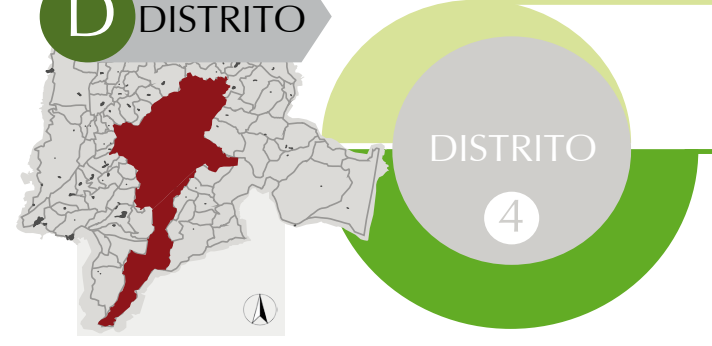 \\ Manejo de los botaderos dentro de los parámetros de sustentabilidad \\ Manejo de política y normativa enfocada en los principios de la ciudad compacta \\ Política clara en cuanto al crecimiento demográfico y a la ocupación del territorio urbano dispoble para tal efecto \\ Aislamientos \\ Áreas útiles \\ Parques metropolitanos \\ Manejo sustentable \\ $4 \mathrm{R}$ \\ Movilidad basada en el transporte eficiente masivo y público \\ Mixtura de usos compatibles, donde la intensidad de usos le dé vida a los sectores \\ Desarrollar espacio público de calidad propicio para las \\ múltiples actividades realizadas allí \\ Densidad habitacional de mínimo 120 viv/ha para justificar todos los usos y la infraestructura de movilidad. \\ Alturas medias para mantener un contacto directo con el espacio público \\ Diversidad de estratos socioeconómicos \\ Diversidad de tejidos y de unidades habitacionales \\ Multiplicar los polos de trabajo y asimismo multiplicar los equipamientos específicos para la población local}

\section{(L) LOCAL
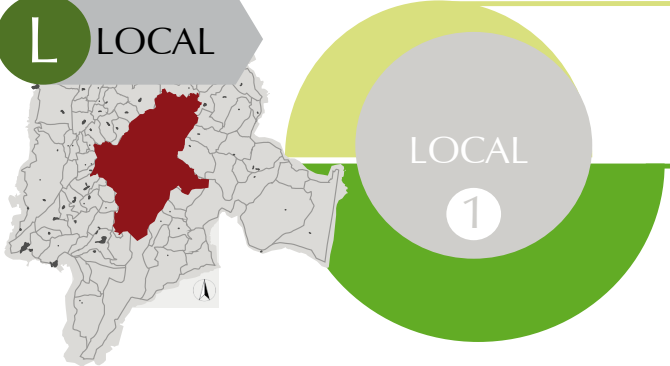 \\ Colegios distritales con horarios extensivos para todos los miembros de la comunidad \\ - Profesionales diferentes ramas - trabajadores sociales - psicólogos- arquitectos - urbanistas- diseñadores- administradores \\ Según el caso específico se deberán hacer las recomendaciones necesarias \\ Educación alternativa experi- Diferentes enfoques especialmente los 5 campos mental y en horarios flexibles específicos para urtilizar las horas libres y $\quad 1$. Sociopolítico $\begin{array}{ll}\text { la ayuda entre las diferentes } \quad 2 \text {. Socioeconómico } & \end{array}$ personas de la comunidad 3. Diseño \\ Establecer claros límites en el 4. Ambiente crecimiento de la población y 5. Resiliencia de los asentamientos}


que las decisiones se toman y ejecutan a través de equipos o, como lo denominan quienes participan de la Eco Aldea Feliz, células autoorganizadas. Cada célula tiene uno o dos líderes como máximo, quienes acuden a la reunión de toma de decisiones en una esfera más reducida (Figura 5).

La especialización de funciones en cada una de las células permite viabilizar la ejecución de las decisiones tomadas, en un proceso que inicia en cada estructura base, la cual se encarga de proponer iniciativas por desarrollar relacionadas con su área de incidencia. Las mismas son presentadas en el "Círculo menor", instancia de coordinación de los líderes de las nueve células, allí no se aprueba o desaprueba, sino que se informa al resto de los integrantes de la Ecoaldea acerca de la ejecución de las iniciativas y los proyectos. Según los líderes entrevistados, tal nivel de autonomía tiene su base en la construcción de confianza a lo largo de los nueve años de actividad continua.

\section{Discusión}

Las comunidades resilientes son posibles en la medida que la comunidad participe y actúe, y que la política pública se implemente y se realice con bases teóricas; para esto es necesario pensar en la densificación y, como se mencionó, tener en cuenta todos los ideales y las teorías de la ciudad compacta expuestas en el libro de Towards an Urban Renaissance (The Urban Task Force, 1999). A nivel distrital tenemos que integrar todas las estrategias, donde la implementación de sistemas de transporte masivo público e integral debe ser la base de la infraestructura de la ciudad. En esta misma línea, la ciudad compacta se caracteriza por minimizar los desplazamientos motorizados y proponer diferentes alternativas para que la población se mueva utilizando los corredores peatonales y las ciclorrutas, que se conectan con la EEP a fin de que se aproveche en doble sentido.

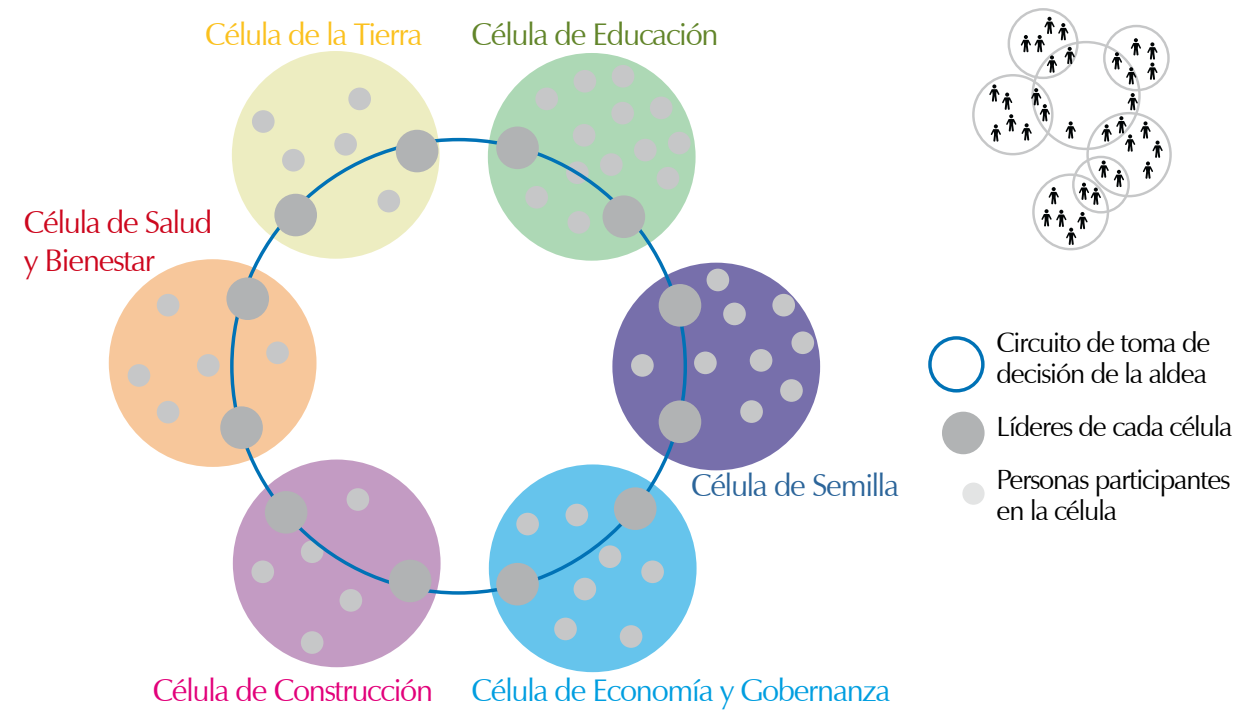

En esta escala, la normativa que se proponga (próximo POT) debe ser una guía, donde las comunidades resilientes puedan realizarse. Para poder llevar a cabo este objetivo deberíamos contar con los siguientes elementos básicos en la planificación:

1. Mixtura de usos compatibles (vivienda, comercio, equipamientos, zonas de trabajo), donde la intensidad de usos le dé vida a los sectores.

2. Desarrollar espacio público de calidad propicio para las múltiples actividades realizadas allí.

3. Multiplicar los polos de trabajo y, así mismo, multiplicar los equipamientos específicos para la población local, que sean específicos o nazcan de las necesidades o identidades que tenga la población.

5. Densidad habitacional de mínimo 120 viv/ha, para justificar todos los usos y la infraestructura de movilidad.

6. Alturas medias para mantener un contacto directo con el espacio público.

7. Diversidad de estratos socioeconómicos.

8. Diversidad de tejidos y de unidades habitacionales.

9. Manejo de energías alternativas, hacia la producción de esta.

Así mismo, la normativa propuesta debe estar estructurada de acuerdo con los ecosistemas presentes dependiendo del lugar en la ciudad y su cercanía con la estructura ecológica principal específica presente en Bogotá.

\section{Los límites de la participación comunitaria en la política pública y el ordenamiento del territorio}

Uno de los retos esenciales de la política pública, tanto para las instancias gubernamentales como para las propias comunidades es el logro efectivo de participación comunitaria, lo que implica diferentes tipos de retos. En primer lugar, se encuentra la necesidad de resignificar la participación ciudadana en la política pública dado que configura una de las grandes promesas incumplidas de la Constitución de 1991.

En las investigaciones más recientes sobre luchas urbanas en Bogotá se puede encontrar que existe una franca preocupación por el análisis de las dinámicas de participación, enfatizando sus límites en el marco de la política pública en la materia. El centro de debate se encuentra en la incidencia de los actores colectivos populares en la construcción de ciudad y el problema de la participación. El trabajo de Noriko Hataya (2010) asume como problema de investigación los cambios en la relación Estado-comunidad en el contexto de la participación comunitaria, y se pregunta por la efectividad de la lucha urbana en el mejoramiento de la calidad de vida en los barrios que analiza. Para ello estudia los procesos de legalización en seis barrios de origen informal en el 
periodo 1992-2003, en las localidades de Ciudad Bolívar, Usme y Rafael Uribe Uribe, ubicados al suroriente de Bogotá, discutiendo las relaciones entre Estado, comunidades y otros actores como iglesias y organizaciones no gubernamentales.

De igual manera, Alfonso Torres (2007) vincula el problema de la participación al proceso nacional y local de descentralización apalancado en la Constitución de 1991; la diferencia estriba en los resultados. Mientras que Torres (2007) afirma que lejos de desactivar la protesta este cambio de orden institucional genera una apertura de las oportunidades políticas que permite el ascenso de la movilización, Hataya (2010) encuentra que la lucha urbana, canalizada por la vía de los mecanismos institucionales de participación comunitaria, pasa de ser efectivamente llamativa para muchos pobladores a desaparecer por desmotivación y desconfianza.

Los autores coinciden en afirmar que, en el marco de la institucionalización del neoliberalismo, la descentralización fue promovida como parte del conjunto de reformas estructurales bajo un discurso democratizador, que prometía una mayor incidencia ciudadana en la política pública a nivel local con fines de legitimación de las instituciones, y buscaba desactivar la protesta urbana en auge desde los años ochenta.

Ahora bien, en la relación entre participación y ordenamiento territorial se encuentra que según la legislación vigente en Colombia, el diseño del Plan de Ordenamiento Territorial (POT) debe contar con la voz y las propuestas de las y los ciudadanos. Los consejos territoriales de planeación son instancias creadas al amparo de la Ley Orgánica de Planeación (Ley 152 de 1994), deben estar conformados por integrantes de la sociedad civil y cumplir el papel de incorporar la visión de la ciudadanía en la organización del territorio. Sin embargo, la configuración de los Consejos Territoriales de Planeación Distrital de Bogotá (CTPD) lesiona el espíritu de participación real ya que es el propio alcalde de Bogotá quien los nombra a partir de ternas presentadas por cada uno de los diferentes sectores que los conforman.

Adicionalmente, la nota predominante en este tipo de escenarios es su carácter meramente consultivo. El escenario distrital presenta un agravante en términos de incidencia efectiva de las y los ciudadanos, ya que los debates entre los técnicos y las decisiones políticas han reducido aún más la participación al restringirla a diferentes acciones de información (Duque, 2010).

Este tipo de estrategia ha hecho que la lógica de ordenamiento del territorio sustentada en dinámicas de concertación entre actores no pase de ser un enunciado, ya que las comunidades, sujetos protagonistas en la construcción del territorio, quedan marginadas de las dinámicas de decisión, tal y como ocurrió tanto en la formulación del POT de 1997 en la primera adminis- tración de Enrique Peñalosa, como en la revisión del mismo en 2003. De acuerdo con el análisis de Isabel Duque (2010), entre 1998 y el año 2000, la Alcaldía Mayor se limitó a realizar reuniones informativas que con exceso de lenguaje técnico no dieron posibilidad de reaccionar a quienes participaban de dichos espacios.

Por todo lo anterior, para un verdadero ordenamiento territorial participativo es necesario que a partir de una relación de mutua determinación entre lo político y lo social, la participación política, social y popular se comprenda en su misma construcción de poder social, popular, ejercido desde la perspectiva colectiva y de construcción social, para el logro efectivo de una "democracia directa de tipo maximalista", capaz de llevar los campos de decisión a la definición del modelo económico, el sistema de justicia y el control de la política, tal y como lo propone el profesor De Zubiría (2012).

Las reglas de juego y las formas de participación y decisión serían la primera gran construcción colectiva de esta forma de poder, conjugada con la definición de agendas, temas, niveles de relevancia de los mismos y tiempos. Por contraste, la denominada democracia participativa, sello particular del régimen político con el que se ha ejecutado el proyecto neoliberal se caracteriza, no por ser construcción colectiva, sino más bien escenario ya establecido al que van a interactuar los procesos populares, sociales y ciudadanos. Los asuntos por tratar y la dinámica de participación están establecidos de antemano, haciendo énfasis en el carácter consultivo de tal participación. De ahí que, según la Constitución Política en su artículo 107, los mecanismos de participación del pueblo se restrinjan al voto, el plebiscito, el referendo, la consulta popular, el cabildo abierto, la iniciativa legislativa y la revocatoria del mandato, todos reglamentados por la ley.

\section{Experiencias y demandas de las comunidades en Bogotá}

Los habitantes de la ciudad de Bogotá han demostrado no ser meros receptores de política pública sino sujetos constructores de la misma, tal y como acontece con la plataforma organizativa Mesa de los Cerros Orientales, gestada desde 2004 por pobladores de barrios ubicados en esta zona de la ciudad. La trayectoria social, política y organizativa de este proceso les ha permitido realizar un tránsito de la exigencia a la propuesta en términos de sus reivindicaciones, generando propuestas de política pública que necesariamente deben ser incorporadas a cualquier ejercicio de planeación.

El primer grupo de propuesta de política pública fue publicado en 2008 por la Mesa de los Cerros Orientales, y reúne tanto un diagnóstico territorial como un conjunto de propuestas realizadas por diversos colectivos de trabajo, organizaciones de base, grupos de vecinos y Juntas de Acción Comunal. Con tales insumos, la Mesa configuró propuestas en diez ejes de acción e incidencia: 
- Hábitat digno y gestión integral de riesgos ambientales.

- Pactos de borde.

- Producción agroecológica.

- Mejoramiento integral de ecobarrios.

- Preservación y uso público para todos y todas.

- Juventud y cerros orientales.

- Educación ambiental.

- Generación de empleo e ingreso productivo ambiental local.

- Restauración ecológica.

- Recuperación geomorfológica.

El citado caso pone de manifiesto cómo la configuración de procesos organizativos es base de primer orden en la definición de política pública para la sostenibilidad, y evidencia tanto el papel de la acción colectiva en la construcción y el ordenamiento del territorio, como las construcciones de política pública que no son de perfil tecnocrático y que se enraizan en las gestiones propias del espacio hecho desde la acción social.

De tal manera, es importante que las diferentes instancias del gobierno distrital tomen en cuenta que muchas de las comunidades asentadas en los bordes urbanos han tenido experiencias organizativas de diferente tipo a lo largo de su historia como constructores de ciudad, desde los procesos de ocupación inicial en las décadas de los cincuenta, sesenta y setenta, hasta la articulación contemporánea en plataformas y comités para hacer frente a distintas políticas como el reasentamiento, o en función del mejoramiento de barrios. En tal sentido, el papel de la institucionalidad no debe ser el de señalar a las comunidades el rumbo que deben seguir, sino apoyar escenarios de encuentro entre experiencias y generar soporte para que proyectos de las comunidades, la academia o diversas organizaciones no gubernamentales puedan efectivamente ser realizadas. Las definiciones internas de las comunidades deben ser resorte de estas mismas, bajo parámetros de autonomía.

\section{Conclusiones}

Desde la perspectiva de la resiliencia comunitaria, la construcción de sostenibilidad en lo barrial es un proceso que no se puede abordar endógenamente, sino que debe tener en cuenta el conjunto de flujos, tránsitos, intercambios y tensiones que se generan tanto al interior del barrio como en la relación que este construye con el entorno. Se trata, por tanto, de comprender que el barrio no es una identidad aislada, sino una construcción social que configura múltiples interacciones con otras escalas de configuración de ciudad. La perspectiva de comunidades resilientes aquí propuesta se vincula a una mirada de conjunto que problematiza las condiciones de la ciudad y la región de la que hace parte, ya que se trata de un concepto que interpela el actual modelo de crecimiento y configuración de la ciudad, enfatizando en los aportes que pueden y deben desarrollarse desde la escala de lo barrial.

Como se observa, la noción de comunidad resiliente trabajada a lo largo de la investigación enfatiza en el carácter social, al tratarse de una construcción realizada por sujetos que se comprenden desde la potencialidad transformadora de lo colectivo, para construir una relación distinta con el ambiente, capaz de tomar distancia frente a la lógica de mercantilización y subordinación para el usufructo humano. Lo anterior a partir de recoger parte de las enseñanzas que dejan las experiencias que hasta el momento se han dado en Bogotá, de acuerdo con las cuales el factor determinante para el logro efectivo de una relación distinta comunidad-ambiente se encuentra en las dinámicas organizativas.

En la medida en que la amplia participación y decisión social se consideran como criterios fundamentales, es factible ubicar un punto de encuentro interesante entre el concepto propuesto y los debates más recientes relacionados con el derecho a la ciudad, los cuales recogen el legado de Henri Lefébvre en su obra pionera de 1967 que reivindica la ciudad como un ejercicio de construcción colectiva, en la cual los habitantes urbanos se apoderan de sus espacios y vidas, no solo para hacerle frente a la exclusión derivada de dinámicas urbanas centradas en las lógicas del capital, sino para la creación misma de la ciudad (Costes, 2011).

Las acciones por emprender en procura de fortalecer el protagonismo de las comunidades en el tránsito hacia dinámicas sostenibles en una ciudad como Bogotá necesariamente deben ampararse en el fortalecimiento de sujetos colectivos empoderados frente al territorio que habitan y han construido históricamente, para realizar interlocución con las diferentes dinámicas de la institucionalidad.

\section{Resignificar el territorio en un ordenamiento territorial participativo}

La acción social de los sujetos construye territorialidades. Al planificar el uso del territorio no se está realizando una mera acción mecánica de distribución de funciones y usos, sino que se está realizando un proceso de significación del mismo, se le dota de sentido y se configuran talanqueras para la creación de realidades y relaciones sociales. No es un ejercicio netamente técnico, sino esencialmente político dado que puede configurar, definir, realinear o transformar las asimetrías de poder y las lógicas de dominación que se dan en el territorio.

Lo anterior exige partir de un concepto de territorio que vaya más allá de considerarlo como espacio o como contenedor de objetos. En tal sentido, se comparte lo propuesto por Carlos Walter Porto-Gonçalves, quien afirma que el territorio:

No es algo anterior o exterior a la sociedad. Territorio es espacio apropiado, espacio hecho 
cosa propia, en definitiva, el territorio es instituido por sujetos y grupos sociales que se afirman por medio de él. Así, hay, siempre, territorio y territorialidad, o sea, procesos sociales de territorialización. En un mismo territorio hay, siempre, múltiples territorialidades (2009, p. 27).

Lo anterior implica que los procesos sociales y la dinámica de las organizaciones populares urbanas transformen espacios en territorios, se territorialicen -expanden el territorio construidoson desterritorializadas - viven la contracción del territorio-, y se reterritorializan -reconfiguran el territorio perdido para volver a la expansión, en una lectura que sigue lo propuesto por Fernandes- (2005).

Desde de esta perspectiva, Bogotá se entiende como territorio en disputa, configurado por sujetos, conflictos y relaciones de poder de diversa índole, por lo que se precisa interpelar y reconocer el carácter de la acción social y política de las organizaciones populares urbanas desde la perspectiva socioterritorial. Un ejercicio de ordenamiento territorial participativo necesariamente debe analizar cómo las formas de organización, las relaciones sociales y la construcción de identidades configuran espacios y territorios desde la acción colectiva.

Cada realidad, cada sector, evidencia problemáticas diferentes que deben ser afrontados por la comunidad que se proponga establecer relaciones no utilitarias con el ambiente, y así contribuir al logro del buen vivir. No obstante, los proyectos por ejecutar no pueden desdibujar el objetivo trascendente de logro de sostenibilidad ambiental y búsqueda de la resiliencia.

Lo anterior implica que debe existir un proceso de diálogo real y conjunto que permita puntos de encuentro entre los intereses de las comunidades, las iniciativas de la academia, del tercer sector y el Gobierno. Pero el primer paso se encuentra en la generación de procesos a nivel de barrio y desde la comunidad. En este proyecto de investigación se han compilado y generado algunas iniciativas que bien pueden ser asumidas por las comunidades y los grupos de líderes que tengan como propósito construir comunidades resilientes.

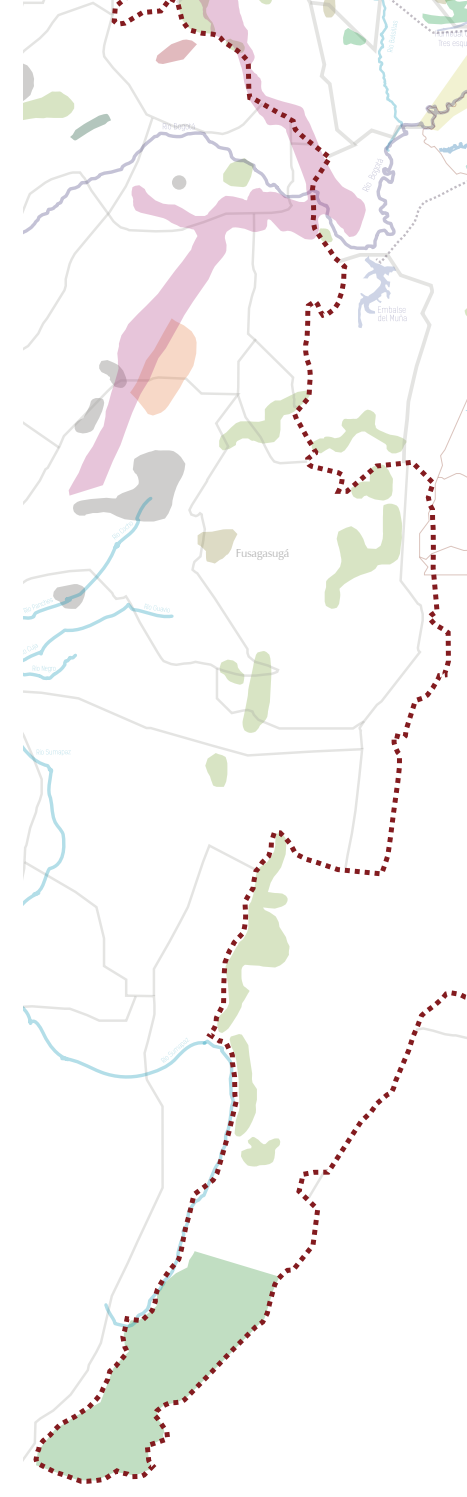

\section{Referencias}

Álvarez, H. (2010). Pensando en Ecobarrios. Una propuesta a las políticas de reasentamiento y las políticas de Hábitat. Bogotá: Cinep.

Azkarraga, J. (2014). Resiliencia local y comunitaria frente a la crisis sistémica. En Madariaga, J. M. Nuevas miradas sobre la resiliencia: ampliando ámbitos y práctias. (pp. 85-110). Barcelona: Gedisa.

Bartin, H. (1999). Sustainable Communities: The Potential for Eco-Neighborhoods. London: Routledge.

Carrizosa, J. y Ruiz, J. (2016, 7 febrero). ¿Llegó la hora de frenar el crecimiento de Bogotá? El Espectador. Recuperado de http://www.elespectador.com/vivir/llego-hora-de-frenarbogota-articulo-615151

CEACSC (2014). Seguimiento y caracterización del embarazo en adolescentes. Secretaría de Gobierno [visitado 2016 ene 29]. Disponible en: http://www.ceacsc.gov.co/index.php/ que-hacemos/componentes-permanentesde-investigacion/seguimiento-y-caracterizacion-del-embarazo-en-adolescentes

Costes, L. (2011). Del "derecho a la ciudad" de Henri Lefebvre a la universalidad de la urbanización moderna. Urban, 2:89-100. Recuperado de: https://dialnet.unirioja.es/ servlet/articulo?codigo $=3762679$

Decreto 364 de 2013 [Alcaldía Mayor de Bogotál. Por el cual se modifican excepcionalmente las normas urbanísticas del Plan de Ordenamiento Territorial de Bogotá D. C., adoptado mediante Decreto Distrital 619 de 2000, revisado por el Decreto Distrital 469 de 2003 y compilado por el Decreto Distrital 190 de 2004.

Decreto 3600 de 2007 [Ministerio del Medio Ambiente]. Por el cual se reglamentan las disposiciones de las Leyes 99 de 1993 y 388 de 1997 relativas a las determinantes de ordenamiento del suelo rural y al desarrollo de actuaciones urbanísticas de parcelación y edificación en este tipo de suelo, y se adoptan otras disposiciones. 20 de septiembre de 2008.

Duque, I. (2010, 1 de agosto). Técnicos, ciudadanos y agendas privadas en la revisión de Plan de Ordenamiento Territorial (POT) de Bogotá. Scripta Nova. Revista Electrónica de Geografía y Ciencias Sociales, XIV (331) 42. Recuperado de: http://www.ub.edu/ geocrit/sn/sn-331/sn-331-42.htm

Duque, My Quintero, J. (2013). La gestión integral del riesgo en territorios urbanos. Nova - Publicación Científica en Ciencias Biomédicas, 11(20), 121-127.

Farr, D. (2007). Sustainable Urbanism: Urban Design with Nature. Hoboken, N.J: Wiley.

Fernandes, B. M. (2005). Movimentos socioterritoriais e movimentos socioespaciais. Contribuição teórica para uma leitura geográfica dos movimentos sociais. OSAL: Observatorio Social de América Latina, 6 (16), 273-283.

Hataya, N. (2010). La ilusión de la participación comunitaria. Lucha y negociación en los barrios irregulares de Bogotá, 1992-2003. Bogotá: Universidad Externado de Colombia.

Lefébvre, H. (1967). El derecho a la ciudad. Barcelona: Península.

Ley 152 de 1994. Por la cual se establece la Ley Orgánica del Plan de Desarrollo. 15 de julio de 1994. D.O. No. 41450

Ley 1454 de 2011. Por la cual se dictan normas orgánicas sobre ordenamiento territorial y se modifican otras disposiciones. 28 de junio de 2011. D.O. No. 48115.

López, D. y Jaramillo, L. M. (25 de mayo de 2015). La experiencia en la Ecoaldea Feliz. (S. C. Bautista y S. Acosta, entrevistadores).

Mc Donough (2002). Cradle to Cradle: Remaking the Way We Make Things. New York: North Point Press.
Madariaga, J. (coord.) (2014). Nuevas miradas sobre la resiliencia. Barcelona: Gedisa.

Novillo, P. (2015, 26 de abril). Viaje al interior del gigante de la basura. Clarín. Recuperado de http://www.clarin.com/ciudades/ciudad de buenos aires-ceamsebasura_0_rydBzjtP7l.html

Porto-Gonçalves, C. (2009). De saberes y de territorios: diversidad y emancipación a partir de la experiencia latino-americana. Polis. Revista de la Universidad Bolivariana, 8 (22), 121-136. Recuperado de: https:// polis.revues.org/2636

Rogers, R. (2000). Ciudades para un pequeño planeta. Barcelona: Gustavo Gili.

Rojas, C. (2003). El proyecto Ecobarrios. Descripción y reflexión acerca de sus objetivos, metodología, impacto y aprendizajes. Bogotá: Alcaldía de Bogotá.

The Urban Task Force (1999). Toward an Urban Renaissance. London: Routledge.

Torres, A. (2007). Identidad y política de la acción colectiva. Organizaciones populares y luchas urbanas en Bogotá 19802000. Bogotá: Universidad Pedagógica de Colombia.

Zubiría, S. d. (2012). Dilemas y desafíos de la participación política. Revista Izquierda, 29, 46-53. Recuperado de https://otramiradadelconflicto.wikispaces.com/file/view/DIL EMAS + Y + DESAF\%C3\%8DOS + DE + LA + P ARTICIPACI $\%$ C3\%93N+POL $\%$ C3\%8DTICA + Sergio+de+Zubir\%C3\%ADa+S..pdf 
La postulación de un artículo a la Revista de Arquitectura indica que- el o los autores certifican que conocen y aceptan la política editorial, para lo cual firmarán en original y remitirán el formato RevArq FP00 Carta de originalidad.

La Revista de Arquitectura maneja una política de Autoarchivo VERDE, según las directrices de SHERPA/RoMEO, por lo cual el autor puede:

- Pre-print del autor: Archivar la versión pre-print (la versión previa a la revisión por pares)

- Post-print del autor: Archivar la versión post-print (la versión final posterior a la revisión por pares

- Versión de editor/PDF: Archivar la versión del editor - PDF/HTML/XLM en la maqueta de la Revista de Arquitectura.

El Autoarchivo se debe hacer respetando la licencia de acceso abierto, la integridad y la imagen de la Revista de Arquitectura, también se recomienda incluir la referencia, el vínculo electrónico y el DOI.

El autor o los autores son los titulares del Copyright (c) del texto publicado y la Editorial de la Revista de Arquitectura solicita la firma de una autorización de reproducción del artículo (RevArq FP03 Autorización reproducción), la cual se acoge a la licencia CC, donde se expresa el derecho de primera publicación de la obra.

La Revista de Arquitectura se guía por las normas internacionales sobre propiedad intelectual y derechos de autor, y de manera particular el artículo 58 de la Constitución Política de Colombia, la Ley 23 de 1982 y el Acuerdo 172 del 30 de septiembre de 2010 (Reglamento de propiedad intelectual de la Universidad Católica de Colombia).

Para efectos de autoría y coautoría de artículos se diferencian dos tipos: "obra en colaboración" y "obra colectiva". La primera es aquella cuya autoría corresponde a todos los participantes al ser fruto de su trabajo conjunto. En este caso, quien actúa como responsable y persona de contacto debe asegurar que quienes firman como autores han revisado y aprobado la versión final, y dan consentimiento para su divulgación. La obra colectiva es aquella en la que, aunque participan diversos colaboradores, hay un autor que toma la iniciativa, la coordinación y realización de dicha obra. En estos casos, la autoría corresponderá a dicha persona (salvo pacto en contrario) y será suficiente únicamente con su autorización de divulgación.

El número de autores por artículo debe estar justificado por el tema, la complejidad y la extensión, y no deberá ser superior a la media de la disciplina, por lo cual se recomienda que no sea mayor de cinco. El orden en que se enuncien corresponderá a los aportes de cada uno a la construcción del texto, se debe evitar la autoría ficticia o regalada. Si se incluyen más personas que trabajaron en la investigación se sugiere que sea en calidad de colaboradores o como parte de los agradecimientos. La Revista de Arquitectura respetará el número y el orden en que figuren en el original remitido. Si los autores consideran necesario, al final del artículo pueden incluir una breve descripción de los aportes individuales de cada uno de firmantes.

La comunicación se establece con uno de los autores, quien a su vez será el responsable de informar a los demás autores de las notificaciones emitidas por la Revista de Arquitectura.

En virtud de mantener el equilibro de las secciones y las mismas oportunidades para todos los participantes, un mismo autor puede postular dos o más artículos de manera simultánea; si la decisión editorial es favorable y los artículos son aceptados, su publicación se realizará en números diferentes.

\section{(A) Acceso abierto}

La Revista de Arquitectura, en su misión de divulgar la investigación y apoyar el conocimiento y la discusión en los campos de interés, proporciona acceso abierto, inmediato e irrestricto a su contenido de manera gratuita mediante la distribución de ejemplares impresos y digitales. Los interesados pueden leer, descargar, guardar, copiar y distribuir, imprimir, usar, buscar o referenciar e texto completo o parcial de los artículos o la totalidad de la Revista de Arquitectura.

\section{(c) (1) (9)}

Esta revista se acoge a la licencia Creative Commons (CC BYNC de Atribución - No comercial 4.0 Internacional): "Esta licencia permite a otros entremezclar, ajustar y construir a partir de su obra con fines no comerciales, y aunque en sus nuevas creaciones deban reconocerle su autoría y no puedan ser utilizadas de manera comercial, no tienen que estar bajo una licencia con los mismos términos"

La Revista de Arquitectura es divulgada en centros y grupos de investigación, en bibliotecas y universidades, y en las principales facultades de Arquitectura, mediante acceso abierto a la versión digital y suscripción anual al ejemplar impreso o por medio de canje, este último se formaliza mediante el formato RevArq FP20 Canjes.

Para aumentar su visibilidad y el impacto de los artículos, se envían a bases de datos y sistemas de indexación y resumen (SIR) y, asimismo, pueden ser consultados y descargados en la página web de la revista.

La Revista de Arquitectura no maneja cobros, tarifas o tasas de publicación de artículo (Article Processing Charge-APC), o por el sometimiento de textos a la publicación.

\section{(1)Ética y buenas prácticas}

La Revista de Arquitectura se compromete a cumplir y respetar las normas éticas en todas las etapas del proceso de publicación. Los autores de los artículos publicados darán cumplimiento a los principios éticos contenidos en las diferentes declaraciones y legislaciones sobre propiedad intelectual y derechos de autor específicos del país donde se realizó la investigación. En consecuencia, los autores de los artículos postulados y aceptados para publicar, que presentan resultados de investigación, deben firmar la declaración de originalidad (formato RevArq FP00 Carta de originalidad).

La Revista de Arquitectura reconoce y adopta los principios de transparencia y buenas prácticas descritos por COPE, "Principles of Transparency and Best Practice in Scholarly Publishing" (2015).

El equipo editorial tiene la obligación de guardar la confidencialidad acerca de los artículos recibidos, y abstenerse de usar en sus propias investigaciones datos, argumentos o interpretaciones hasta tanto el artículo no sea publicado. También debe ser imparcial y gestionar los artículos de manera adecuada y en los plazos establecidos. La selección de revisores se hará con objetividad y estos deberán responder a la temática del artículo.

El editor, los autores y los revisores deben seguir las normas éticas internacionales definidas por el Committee on Publication Ethics (COPE), con el fin de evitar casos de:

- Fabricación, falsificación u omisión de datos.

- Plagio y autoplagio.

- Publicación redundante, duplicada o fragmentada.

- Omisión de referencias a las fuentes consultadas.

- Utilización de contenidos sin permiso o sin justificación.

- Apropiación individual de autoría colectiva.

- Cambios de autoría.

- Conflicto de interés (CDI) no revelado o declarado.

- Otras que pudieran surgir en el proceso de investigación y publicación. La fabricación de resultados se genera al mostrar datos inventados por los autores; la falsificación resulta cuando los datos son manipulados y cambiados a capricho de los autores; la omisión se origina cuando los autores ocultan deliberadamente un hecho o dato. El plagio se da cuando un autor presenta como ideas propias datos creados por otros. Los casos de plagio son los siguientes: copia directa de un texto sin entrecomillar o citar la fuente, modificación de algunas palabras del texto, paráfrasis y falta de agradecimientos; el autoplagio se da cuando el mismo autor reutiliza material propio que ya fue publicado, pero sin indicar la referencia al trabajo anterior. La revista se apoya en herramientas digitales que detectan cualquiera de estos casos en los artículos postulados, y es labor de los editores y revisores velar por la originalidad y fidelidad en la citación. La publicación redundante o duplicada se refiere a la copia total, parcial o alterada de un trabajo ya publicado por el mismo autor

En caso de sospechar de alguna mala conducta se recomienda seguir los diagramas de flujo elaborados por COPE (2008), con el fin de determinar las acciones correspondientes.

La Revista de Arquitectura se reserva el derecho de retractación de publicación de aquellos artículos que, posterior a su publicación, se demuestre que presentan errores de buena fe, o cometieron fraudes o malas prácticas científicas. Esta decisión se apoyará en "Retraction Guidelines" (COPE, 2009). Si el error es menor, este se podrá rectificar mediante una nota editorial de corrección o una fe de erratas. Los autores también tienen la posibilidad de solicitar la retractación de publicación cuando descubran que su trabajo presenta errores graves. En todos los casos se conservará la versión electrónica y se harán las advertencias de forma clara e inequívoca.

\section{(A) Privacidad y manejo de la información.} Habeas Data

Para dar cumplimiento a lo previsto en el artículo 10 del Decreto 1377 de 2013, reglamentario de la Ley 1581 de 2012, y según el Acuerdo 002 del 4 de septiembre de 2013 de la Universidad Católica de Colombia, "por el cual se aprueba el manual de políticas de tratamiento de datos personales":

La Universidad Católica de Colombia, considerada como responsable o encargada del tratamiento de datos personales, manifiesta que los datos personales de los autores, integrantes de los comités y pares revisores, se encuentran incluidos en nuestras bases de datos; por lo anterior, y en cumplimiento de las disposiciones legales vigentes, la Universidad solicitará siempre su autorización, para que en desarrollo de sus funciones propias como Institución de Educación Superior, en especial las relacionadas con la docencia, la extensión y la investigación, la Universidad Católica de Colombia pueda recolectar, recaudar, almacenar, usar, circular, suprimir, procesar, intercambiar, compilar, dar tratamiento, actualizar, transmitir o transferir a terceros países y disponer de los datos que le han suministrado y que han sido incorporados en las bases de datos de todo tipo que reposan en la Universidad.

La Universidad Católica de Colombia queda autorizada, de manera expresa e inequívoca, en los términos señalados por el Decreto 1377 de 2013, para mantener y manejar la información de nuestros colaboradores (autores, integrantes de los diferentes comités y pares revisores); así mismo, los colaboradores podrán ejercer sus derechos a conocer, actualizar, rectificar y suprimir sus datos personales, para lo cual se han dispuesto las siguientes cuentas de correo electrónico: 
La Revista de Arquitectura recibe artículos de manera permanente. Los artículos se procesan a medida que se postulan, dependiendo el flujo editorial de cada sección.

El idioma principal es el español, y como opcionales están definidos el inglés, el portugués y el francés; los textos pueden ser escritos y presentados en cualquiera de estos.

Los artículos postulados deben corresponder a las categorías universalmente aceptadas como producto de investigación, ser originales e inéditos y sus contenidos responder a criterios de precisión, claridad y brevedad.

Como punto de referencia se pueden tomar las tipologías y definiciones del Índice Bibliográfico Nacional, Publindex (2010) que se describen la continuación:

1. Artículo de revisión: documento resultado de una investigación terminada donde se analizan, sistematizan e integran los resultados de investigaciones publicadas o no publicadas, sobre un campo en ciencia o tecnología, con el fin de dar cuenta de los avances y las tendencias de desarrollo. Se caracteriza por presentar una cuidadosa revisión bibliográfica de por lo menos 50 referencias.
2. Artículo de investigación científica y tecnológica: documento que presenta, de manera detallada, los resultados originales de proyectos terminados de investigación. La estructura generalmente utilizada contiene cuatro apartes importantes: introducción, metodología, resultados y conclusiones.

3. Artículo de reflexión: documento que presenta resultados de investigación terminada desde una perspectiva analítica, interpretativa o crítica del autor, sobre un tema específico, recurriendo a fuentes originales.

En todos los casos se debe presentar la información suficiente para que cualquier investigador pueda reproducir la investigación y confirmar o refutar las interpretaciones defendidas.

También se pueden presentar otro tipo de documentos diferentes a los anteriormente descritos, como pueden ser: artículo corto, reporte de caso, revisión de tema, documento resultado de la revisión crítica de la literatura sobre un tema en particular, cartas al editor, traducción, documento de reflexión no derivado de investigación, reseña bibliográfica, así como proyectos de arquitectura o urbanismo, entre otros

\section{(A) Instrucciones para postular artículos}

Postular el artículo en la página web de la Revista de Arquitectura y adjuntar comunicación escrita dirigida al editor RevArq_FP00 Carta de originalidad (debidamente firmada por todos los autores en original); de igual manera, se debe diligenciar el formato de hoja de vida RevArq FP01 Hoja de Vida (una por cada autor).

En la comunicación escrita el autor expresa que conoce y acepta la política editorial de la Revista de Arquitectura, que el artículo no está postulado para publicación simultáneamente en otras revistas u órganos editoriales y que no existe conflicto de intereses (ver modelo RevArq FP06 CDI) y que, de ser aceptado, concederá permiso de primera publicación, no exclusiva a nombre de la Universidad Católica de Colombia como editora de la revista.

Los artículos deben tener en cuenta las siguientes recomendaciones:

- En la primera página del documento se debe incluir:

Título: no exceder 15 palabras.

Subtítulo: opcional, complementa el título o indica las principales subdivisiones del texto.

Nombre del autor o autores: nombres y apellidos completos o según modelo de citación adoptado por el autor para la normalización de los nombres del investigador. Como nota al pie (máximo 150 palabras) formación académica, experiencia profesional e investigativa, vinculación laboral, código ORCID, premios o reconocimientos, publicaciones representativas e información de contacto, correo electrónico.

Filiación institucional: debajo del nombre se debe declarar la institución en la cual se desarrolló el producto, de la cual recibió apoyo o aquella que respalda el trabajo investigativo.

Resumen: debe ser analítico, se redacta en un solo párrafo, da cuenta del tema, el objetivo, la metodología, los resultados y las conclusiones; no debe exceder las 150 palabras.

Palabras clave: cinco palabras o grupo de palabras, ordenadas alfabéticamente y que no se encuentren en el título o subtítulo; estas sirven para clasificar temáticamente al artículo. Se recomienda emplear principalmente palabras definidas en el tesauro de la Unesco (http:// databases.unesco.org/thessp/), en el tesauro de Arte \& Arquitectura (C) (www.aatespanol.cl), o Vitruvio (http://vocabularyserver.com/vitruvio/)

También se recomienda incluir título, resumen y palabras clave en segundo idioma.

- La segunda página y siguientes deben tener en cuenta:

El cuerpo del artículo se divide en: Introducción, Metodología, Resultados y Discusión de resultados; posteriormente se presentan las Conclusiones, y luego las Referencias bibliográficas y los Anexos (método IMRYD). Las tablas y figuras se deben incorporar en el texto.

Descripción del proyecto de investigación: en la introducción se debe describir el tipo de artículo y brevemente el marco investigativo del cual es resultado y diligenciar el formato (RevArq FP02 Info Proyectos de Investigación).

TEXTO: todas las páginas deben venir numeradas y con el título de artículo en la parte superior de la página. Márgenes de $3 \mathrm{~cm}$ por todos los lados, interlineado doble, fuente Arial o Times New Roman de 12 puntos, texto justificado (Ver plantilla para presentación de artículos). La extensión de los artículos debe ser de alrededor de 5.000 palabras ( \pm 20 páginas, incluyendo gráficos, tablas, referencias, etc.); como mínimo 3.500 y máximo 8.000 palabras. Se debe seguir el estilo vigente y recomendado en el Manual para Publicación de la American Psychological Association (APA). (Para mayor información véase http://www.apastyle.org/)
Citas y notas al pie: las notas aclaratorias o notas al pie no deben exceder cinco líneas o 40 palabras, de lo contrario estas deben ser incorporadas al texto general. Las citas pueden ser:

Corta: (con menos de 40 palabras) se incorporan al texto y pueden ser: textuales (se encierran entre dobles comillas), parafraseo o resumen (se escriben en palabras del autor dentro del texto).

Cita textual extensa: (mayor de 40 palabras) debe ser dispuesta en un renglón y un bloque independiente con sangrías y omitiendo las comillas, no olvidar en ningún caso la referencia del autor (Apellido, año, página).

Referencias: como modelo para la construcción de referencias se emplea el estilo recomendado en el Manual para Publicación de la American Psychological Association (APA) (http://www.apastyle.org/).

Siglas: en caso de emplear siglas en el texto, las figuras o las tablas, se debe proporcionar la equivalencia completa la primera vez que se empleen y encerrarlas entre paréntesis. En el caso de citar personajes reconocidos se deben colocar nombres o apellidos completos, nunca emplear abreviaturas.

Figuras y tablas: las figuras (gráficos, diagramas, ilustraciones, planos, mapas o fotografías) y las tablas deben ir numeradas y contener título o leyenda explicativa relacionada con el tema del artículo, que no exceda las 15 palabras (Figura 1. xxxxx, Tabla 1. xxxx, etc.) y la procedencia (fuente: autor o fuente, año, página). Estas se deben referenciar en el texto de forma directa o entre paréntesis; se recomienda hacerlo con referencias cruzadas.

También se deben entregar en medio digital, independiente del texto, en formatos editables o abiertos. La marcación de los archivos debe corresponder a la incluida en el texto. Según la extensión del artículo se deben incluir de 5 a 10 gráficos. Ver guía para la búsqueda de imágenes de dominio público o bajo licencias Creative Commons (CC).

El autor es el responsable de adquirir los derechos o las autorizaciones de reproducción a que haya lugar para imágenes o gráficos tomados de otras fuentes, así como de entrevistas o material generado por colaboradores diferentes a los autores; de igual manera, se debe garantizar la protección de datos e identidades para los casos que sea necesario.

FotografíA: pueden ser entregadas en original para ser digitalizadas, de lo contrario se deben digitalizar con una resolución igual o superior a 300 dpi para imágenes a color y 600 para escala de grises. Los formatos de las imágenes pueden ser TIFF, PSD o JPG, y deben cumplir con las características expresadas en el punto anterior (figuras).

Planimetría: se debe entregar la planimetría original en medio digital, en lo posible en formato CAD, y sus respectivos archivos de plumas o en PDF; de no ser posible, se deben hacer impresiones en tamaño carta con las referencias de los espacios mediante numeración y lista adjunta. Deben tener escala gráfica, escala numérica, norte, coordenadas y localización. En lo posible, no deben contener textos, achurados o tramas.

Para más detalles, consultar el documento RevArq Parámetros para Autores Descripción en el portal web de la Revista de Arquitectura

\section{Beneficios}

Como reconocimiento a los autores, se les hará envío postal de dos ejemplares de la edición impresa sin ningún costo y entregada en la dirección consignada en el formato de hoja de vida (RevArq FP01); adicionalmente, se enviará el vínculo para la descarga de la versión digital.

También se enviará una constancia informativa en la que se relaciona la publicación del artículo y, de manera opcional, se pueden detallar las fechas del proceso editorial y el arbitraje realizado. 
La selección de revisores se realiza de acuerdo con los siguientes criterios:

- Afinidad temática.

- Formación académica.

- Experiencia investigativa y profesional.

- Producción editorial en revistas similares o en libros resultado de investigación.

El proceso de arbitraje se basa en los principios de equidad e imparcialidad, y en los criterios de calidad y pertinencia.

El desarrollo de la revisión se realiza según el formato (RevArq FP10 Evaluación de artículos) y las observaciones que el revisor considere necesarias en el cuerpo del artículo. En cualquiera de los conceptos que emita el revisor (Aceptar, Publicable con modificaciones, Reevaluable o No publicable), y como parte de la labor formativa y de comunidad académica, el revisor hará sugerencias para mejorar el documento. El revisor podrá solicitar una nueva relectura del artículo después de los ajustes realizados por el autor.

El revisor también deberá diligenciar el formato RevArq FP01 Hoja de Vida, con el fin de certificar y soportar el proceso de revisión ante los SIR que así lo soliciten.

En el proceso de arbitraje se emplea el método doble ciego, los nombres del revisor no serán conocidos por el autor y viceversa. Con el fin de garantizar el anonimato del autor, al artículo postulado se le han podido suprimir nombres, instituciones o imágenes que puedan ser asociadas de manera directa al autor.

Aunque se procura el anonimato, una vez recibida la invitación como par revisor del artículo, el revisor debe cerciorarse de que no exista conflicto de intereses (CDI) o alguna limitante que afecte la revisión o que pueda ser vista como tal (lazos familiares, amistad o enemistad, vínculos contractuales o laborales, posiciones éticas, etc.), de presentarse esta situación se notificara al editor. (Ver modelo RevArq FP06 CDI)

Dada la confidencialidad del proceso de revisión, y considerando los derechos de autor y de propiedad intelectual que pueda haber sobre el material que se entrega, el revisor se compromete a mantener en absoluta reserva su labor, a limitar el uso de la obra entregada solo para el propósito designado y a devolver la documentación remitida una vez concluya la actividad.

El tiempo establecido para las revisiones de pares es de máximo un mes a partir de la confirmación de la recepción de la documentación. Ese plazo podrá ser modificado de mutuo acuerdo entre el editor y el revisor, siempre y cuando no afecte la periodicidad de la revista, la impresión o el tiempo para emitir una respuesta al autor. Los revisores se acogerán a "COPE Ethical Guidelines for Peer Reviewers" de COPE.

\section{Beneficios}

Como retribución a los revisores se les hará envío postal de un ejemplar de la edición impresa sin ningún costo y entregada en la dirección consignada en el formato de hoja de vida. También, si es de interés para el revisor, podrá hacer la solicitud de alguna de las publicaciones editadas y presentes en el catálogo de publicaciones de la UNIVERSIDAD CATÓlica DE Colombia, previa aprobación de la Editorial y sujeto a la disponibilidad.

Si lo desea tendrá derecho a una constancia de la colaboración en la revisión de artículos, la cual solo contendrá el periodo en el cual se realizó la actividad. También tendrá la posibilidad de aceptar o no la publicación de su nombre, nacionalidad y nivel máximo de formación en la página web de la Revista de Arquitectura en su calidad de colaborador.

\section{A Proceso de revisión por pares}

Luego de la postulación del artículo, el editor de la Revista de Arquitectura selecciona y clasifica los artículos que cumplen con los requisitos establecidos en las directrices para los autores. El editor podrá rechazar en primera instancia artículos, sin recurrir a un proceso de revisión, si los considera de baja calidad o por presentar evidencias de faltas éticas o documentación incompleta.

Los artículos se someterán a un primer dictamen del editor, de los editores de sección y del Comité Editorial, teniendo en cuenta:

- Afinidad temática, relevancia del tema y correspondencia con las secciones definidas.

- Respaldo investigativo.

- Coherencia en el desarrollo del artículo, así como una correcta redacción y ortografía.
- Relación entre las figuras y tablas con el texto del artículo.

En esta revisión se verificará el nivel de originalidad mediante el uso de software especializado (Ithenticate o similar) y recursos digitales existentes para tal fin, también se observará la coherencia y claridad en los apartados del documento (modelo IMRYD), la calidad de las fuentes y la adecuada citación, esto quedará consignado en el formato (RevArq FP09 Revisión de artículos); esta información será cargada a la plataforma de gestión editorial y estará a disposición del autor.

En caso de que el artículo requiera ajustes preliminares, será devuelto al autor antes de ser remitido a revisores. En este caso, el autor tendrá veinte días para remitir nuevamente el texto con los ajustes solicitados.

Después de la preselección se asignan mínimo dos revisores especializados, quienes emitirán su concepto utilizando el formato (RevArq FP10 Evaluación de artículos) y las anotaciones que consideren oportunas en el texto; en esta etapa se garantizará la confidencialidad y el anonimato de autores y revisores (modalidad doble ciego)

Del proceso de revisión se emite uno de los siguientes conceptos que será reportado al autor:

- Aceptar el envío: con o sin observaciones.

- Publicable con modificaciones: se podrá sugerir la forma más adecuada para una nueva presentación, el autor puede o no aceptar las observaciones según sus argumentos. Si las acepta cuenta con quince días para realizar los ajustes pertinentes.

- Reevaluable: cumple con algunos criterios y debe ser corregido. Es necesario hacer modificaciones puntuales y estructurales al artículo. En este caso, el revisor puede aceptar o rechazar hacer una nueva lectura del artículo luego de ajustado.

- No publicable: el autor puede volver a postular el artículo e se evidencien los ajustes correspondientes.

En el caso de presentarse diferencias sustanciales y contradictorias en los conceptos sobre la recomendación del revisor, el editor remitirá el artículo a un revisor más o a un miembro del Comité Editorial quien podrá actuar como tercer árbitro, con el fin de tomar una decisión editorial sobre la publicación del artículo.

Los autores deberán considerar las observaciones de los revisores o de los editores, y cada corrección incorporada u omitida debe quedar justificada en el texto o en una comunicación adjunta. En el caso que los autores omitan las indicaciones realizadas sin una argumentación adecuada, el artículo será devuelto y no se dará por recibido hasta que no exista claridad al respecto.

El editor respetará la independencia intelectual de los autores y a estos se les brindará el derecho de réplica en caso de que los artículos hayan sido evaluados negativamente y rechazados.

Los autores, con su usuario y contraseña, podrán ingresar a la plataforma de Gestión Editorial, donde encontrarán los conceptos emitidos y la decisición sobre el artículo.

El editor y el Comité Editorial se reservan el derecho de aceptar o no la publicación del material recibido. También se reservan el derecho de sugerir modificaciones de forma, ajustar las palabras clave o el resumen y de realizar la corrección de estilo. El autor conocerá la versión final del texto antes de la publicación oficial del mismo.

Cuando un artículo es aceptado para su publicación, el autor debe firmar la autorización de reproducción (RevArq FP03 Autorización reproducción). Para más información ver: Política de derechos de autor

\section{Notas aclaratorias:}

La Revista de Arquitectura publica un número limitado de artículos por volumen y busca el equilibrio entre las secciones, motivo por el cual, aunque un artículo sea aceptado o continúe en proceso de revisión, podrá quedar aplazado para ser publicado en un próximo número; en este caso, el autor estará en la posibilidad de retirar la postulación del artículo o de incluirlo en el banco de artículos del próximo número.

El editor y los editores de sección de la Revista de Arquitectura son los encargados de establecer contacto entre los autores y revisores, ya que estos procesos se realizan de manera anónima. iniciar nuevamente el proceso de arbitraje, siempre y cuando
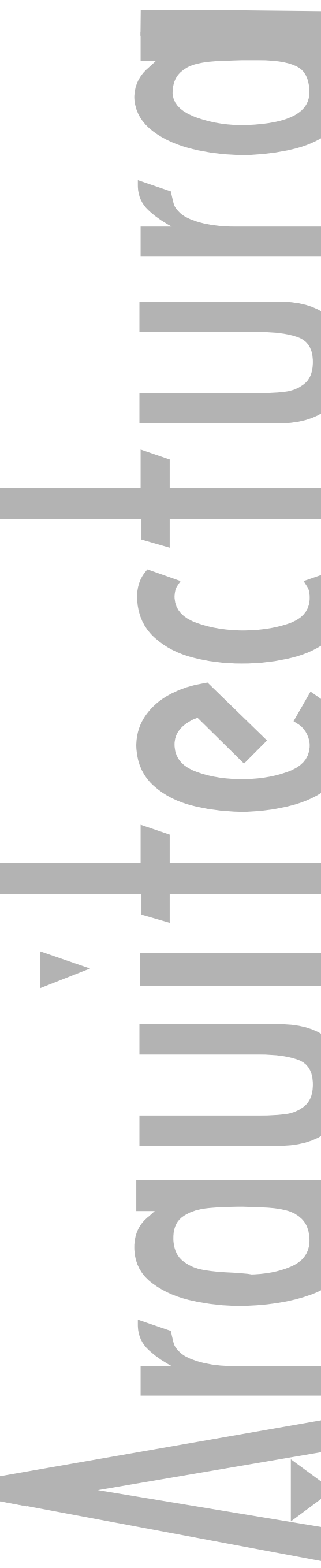

Vol.

Nro. 22017 


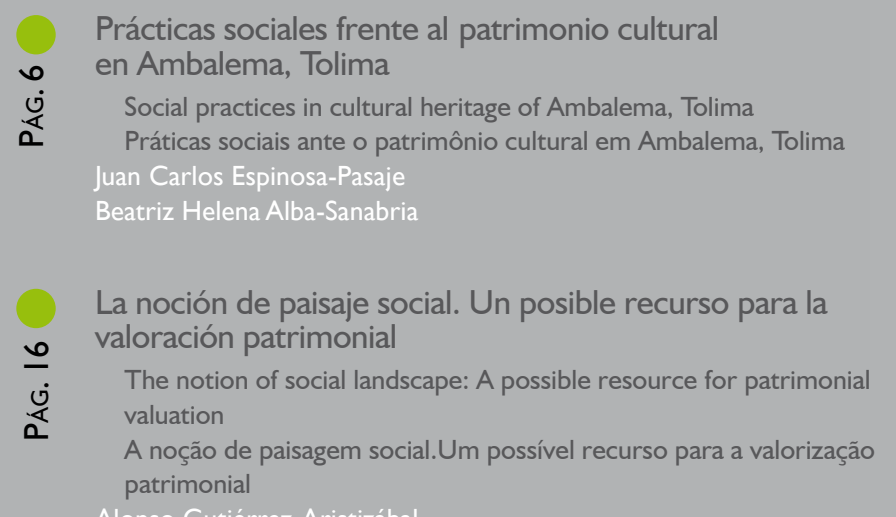

Cuadros de una exposición: promenade architectural por la
obra de Eduardo de Almeida
$\dot{0}$ Pictures at an Exhibition: A promenade architectural through the work of
$\dot{\cup}$ Eduardo de Almeida
Quadros de uma exposição: promenade architecturale pela obra de
Eduardo de Almeida

Evaluación posocupacional del grado de satisfacción

* de los trabajadores. Instituto de Planificación y Promoción de

F Soluciones Energéticas para Zonas no Interconectadas (IPSE)

¿ Post-occupancy evaluation of workers' degree of satisfaction. Institute

for Planning and Promotion of Energy Solutions for Non-Interconnected Zones (IPSE)

Avaliação pós-ocupacional do grau de satisfação dos trabalhadores Instituto de Planificación y Promoción de Soluciones Energéticas para Zonas no Interconectadas (IPSE)

Mónica Dávila-Valencia

Andrés Felipe Ortiz-Silva

Comunidades resilientes: tres direcciones integradas

Resilient Communities: Three Integrated Directions

Ho Comunidades resilientes: três
¿
¿ Sandra Acosta-Guacaneme

Innovación, design y sostenibilidad social: nuevas tendencias para el desarrollo local en la contemporaneidad

$\infty$

这

Inovação, design e sustentabilidade social: novas tendências para o desenvolvimento local na contemporaneidade

Rodrigo Rocha-Carneiro

Intervención social en el borde urbano desde el proceso de la significación cultural

Social intervention on the urban edge from the perspective of cultural

ن significance

¿ Intervenção social na periferia urbana a partir do processo da significação cultural

Fabián Adolfo Aguilera-Martínez

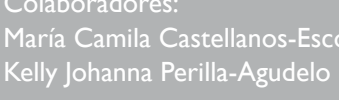

Vectores de una cartografía teórica: una brújula de navegación para un océano de tesis doctorales en arquitectura

¿ Un compas des théories dans l'océan doctoral en architecture

Vectors for a theoretical cartography: A navigation compass for an ocean ن of doctoral theses in architecture

Vetores de uma cartografia teórica: uma bússola de navegação para um oceano de teses doutorais em arquitetura

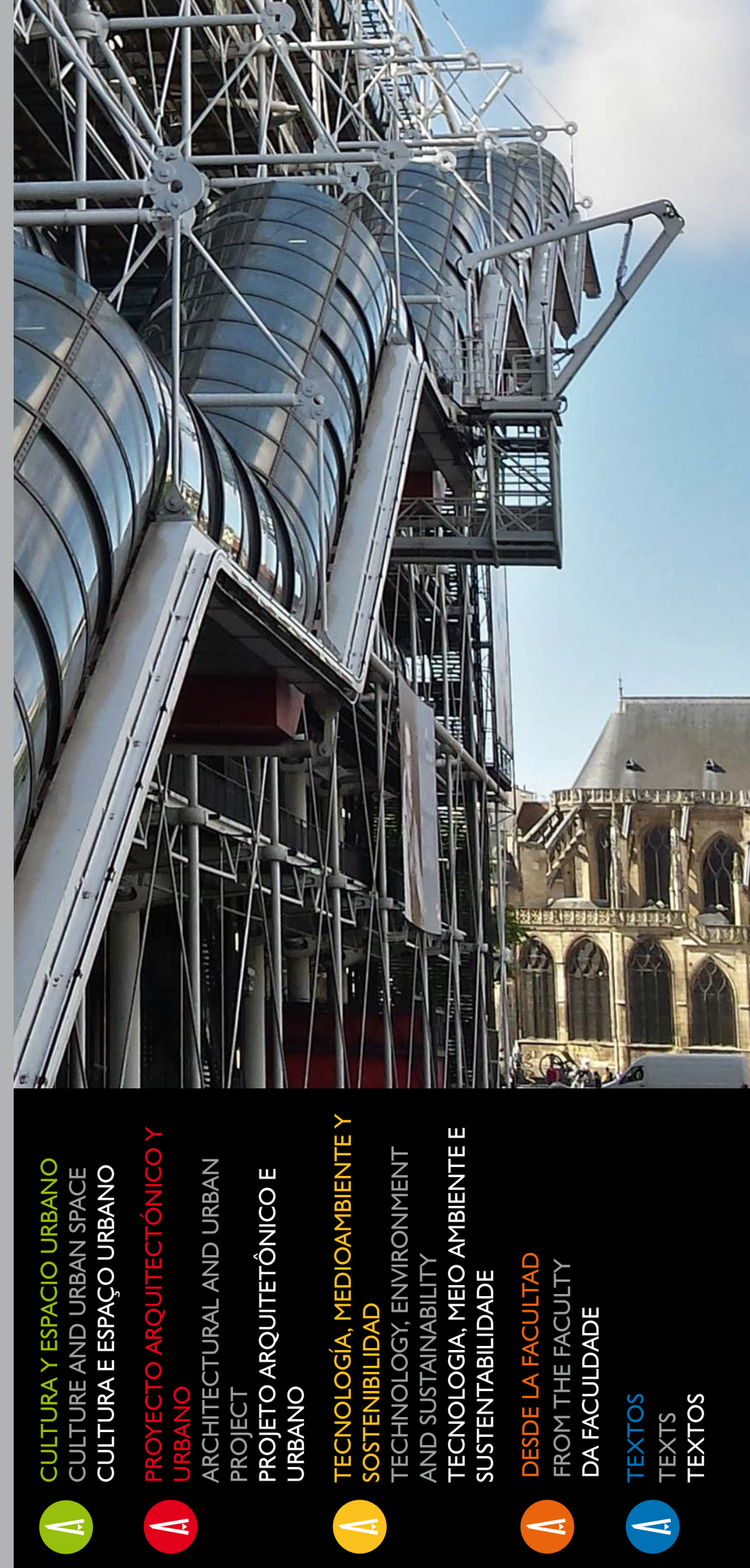

La Revista de Arquitectura es de acceso abierto, arbitrada e indexada y está presente en:
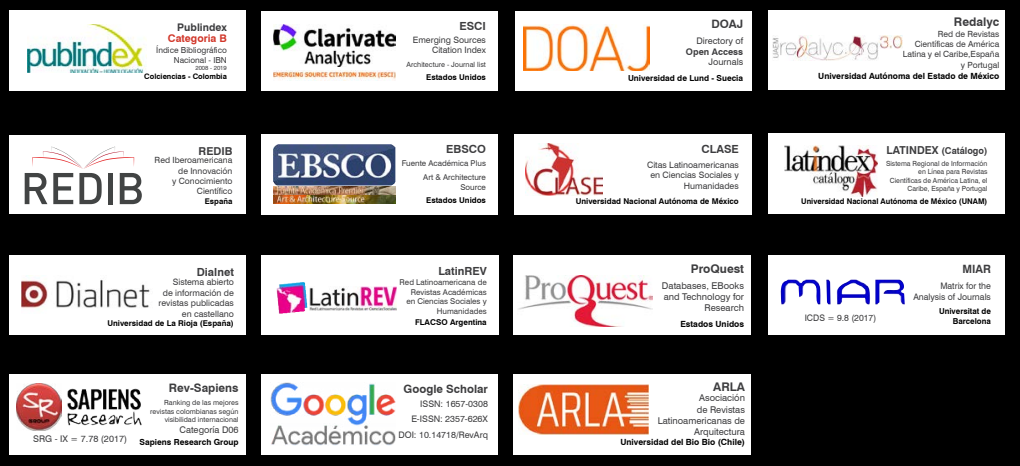

$f^{2}$
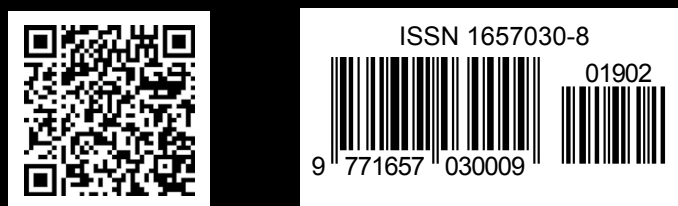